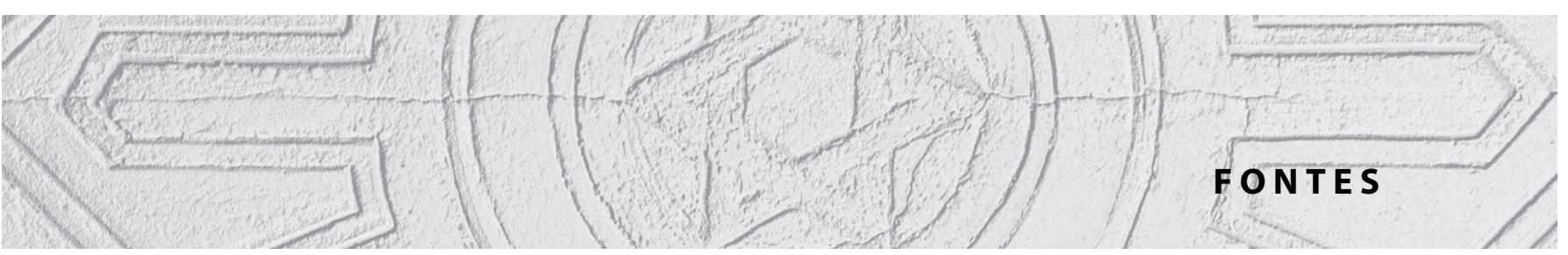

\title{
O Regimento dos preços dos medicamentos... na farmácia brasileira oitocentista
}

\author{
Regulation of drug prices in nineteenth-century \\ Bazilian pharmacy
}

\author{
Amanda Peruchi ${ }^{i}$ \\ ' Doutoranda, Faculdade de Ciências \\ Humanas e Sociais/Universidade \\ Estadual Paulista "Júlio de Mesquita \\ Filho". \\ Franca - SP - Brasil \\ orcid.org/0000-0002-7362-2252 \\ amandaperuchi@outlook.com
}

Recebido em 21 jan. 2019.

Aprovado em 8 abr. 2019.
PERUCHI, Amanda. O Regimento dos preços dos medicamentos... na farmácia brasileira oitocentista. História, Ciências, Saúde - Manguinhos, Rio de Janeiro, v.27, n.3, jul.-set. 2020, p.933-965.

\section{Resumo}

Em 5 de novembro de 1808, dom João de Bragança promulgou um alvará sobre o exercício dos boticários e o preço das drogas e ordenou a criação de um regulamento para taxar o custo dos medicamentos comercializados no Brasil. Publicado pela primeira vez em 1809, o Regimento dos preços dos medicamentos... ganhou novas edições nos anos subsequentes e tornouse um indispensável instrumento de trabalho para os envolvidos com a feitura e o comércio dos remédios. Este texto situa historicamente e destaca esse documento brevemente explorado pelos pesquisadores da história da farmácia brasileira, visto ter sido uma das primeiras iniciativas do governo luso-brasileiro condizentes com a atividade farmacêutica no Brasil no século XIX.

Palavras-chave: história da farmácia; remédios; Brasil; século XIX.

Abstract

On November 5th, 1808, D. João de Bragança issued a license about the practice of druggists and the price of drugs and ordered the creation of a regulation to tax the cost of medicines marketed in Brazil. First published on 1809, the Regimento dos preços dos medicamentos... gained new editions in the following years and became an indispensable working tool for those involved in the making and trading of drugs at this time. This paper situates historically and sheds light on a document briefly explored by the researchers of the history of the Brazilian pharmacy, taking into account that it was one of the first initiatives of the Luso-Brazilian government in line with the pharmaceutical activity in Brazil in the nineteenth century.

Keywords: pharmacy history; drugs; Brazil; XIX century.

http://dx.doi.org/10.1590/\$0104-59702020000400013 
$\mathrm{N}$ o último dia de 1809, veio à luz na cidade do Rio de Janeiro, pela tipografia da Impressão Régia, o Regimento dos preços dos medicamentos símplices, preparados e compostos, assim como se descrevem na Farmacopeia Geral do Reino, feito e publicado por ordem de Sua Alteza Real, o príncipe regente, nosso senhor, para governo dos boticários nos estados do Brasil (Anúncios, 31 dez. 1809). Trata-se de um pequeno livro, de 44 páginas, que nos ajuda a contar um pouco da história da farmácia brasileira oitocentista, especificamente dos remédios, suas taxas e composições, e da regularização do exercício profissional dos homens envolvidos com a feitura de medicamentos. Elaborado pelo então físico-mor do Reino, o médico português Manoel Vieira da Silva (1753-1826), ${ }^{1}$ o Regimento dos preços dos medicamentos... faz parte, como veremos, de uma série de ações do governo luso-brasileiro em relação à atividade farmacêutica no Brasil nas primeiras décadas do século XIX.

Nessa época, os ofícios de curar em terras brasileiras eram regulamentados pela Fisicaturamor, recriada pelo príncipe regente, dom João de Bragança, em 7 de fevereiro de $1808 .^{2}$ Organizada a partir dos cargos de físico-mor e cirurgião-mor do Reino e seus comissários delegados, a Fisicatura-mor já tinha fiscalizado as atividades curativas em Portugal e seus domínios entre meados do século XV e final do XVIII, quando foi substituída pela Junta do Protomedicato, por ordem da rainha dona Maria I, em 1782. A Junta do Protomedicato, a exemplo de sua antecessora, objetivava um amplo programa de controle da saúde pública, impondo leis mais rigorosas e intensificando a luta contra o curandeirismo, o charlatanismo ou qualquer outra atividade paralela; seu propósito era supervisionar e extinguir as práticas efetuadas sem as licenças e, portanto, de forma clandestina (Ribeiro, 1997, p.130; Abreu, 2011, p.122).

No Brasil, nos três primeiros séculos de domínio dos portugueses, seja na época da Fisicatura-mor ou da Real Junta do Protomedicato, todos aqueles que desejavam curar tinham que possuir cartas de exames e registros a fim de solicitar as licenças para exercer a profissão médica, cirúrgica ou farmacêutica (Ribeiro, 1997, p.127). Além disso, caso os comissários delegados desses órgãos estivessem ausentes - o que, aliás, acontecia com certa frequência, dada à distância entre a metrópole e a colônia, bem como à extensão do território colonial -, as Câmaras Municipais podiam autorizar os interessados nas artes da curar (Abreu, 2011, p.26). No entanto, apesar desse esforço luso-brasileiro, muitos profissionais atuavam sem as licenças ou qualquer interferência dos órgãos reguladores (Ribeiro, 1997, p.127).

No início do século XIX, tendo em vista a necessidade de organizar diferentes setores da nova sede da Coroa com a vinda da família real portuguesa, a saúde pública ganhou atenção do governo com uma série de determinações que buscavam melhorar a formação e o exercício dos profissionais envolvidos com as atividades terapêuticas (Schwarcz, Azevedo, Costa, 2002, p.250; Araújo, 1979, p.34). Nesse novo cenário, o príncipe regente, como já apontado, restabeleceu a Fisicatura-mor e nomeou Manoel Vieira da Silva e José Correia Picanço (1745-1823) ${ }^{3}$ para as funções de físico-mor e cirurgião-mor do Reino, respectivamente. A Fisicatura-mor, que passava a ser sediada no Brasil, segundo o seu próprio regimento - documento que regulava sua atuação -, contribuiria com "o aumento e conservação da saúde pública, fazendo desarreigar antigos e prejudiciais abusos, e dando todas as providências que forem análogas e conducentes a tão importante objeto" (Brasil, 1891b, p.163; Pimenta, 1997, p.21-22). A partir de então, os profissionais das atividades 
curativas tinham de atender aos requisitos previamente estipulados e novamente pedir autorização e licença à Fisicatura-mor (Pimenta, 2003, p.93).

Umas das primeiras medidas efetivadas na retomada da Fisicatura-mor foi a confecção de um estudo acerca das principais causas determinantes das doenças da população (Ribeiro, 1992, p.21-22), feito pelo físico-mor a pedido do príncipe regente e que originou o primeiro texto médico publicado no Brasil: Reflexões sobre alguns dos meios propostos por mais conducentes para melhorar o clima da cidade do Rio de Janeiro. Nesse trabalho, o autor foi enfático ao registrar que a maior parte das doenças decorria do clima quente e úmido da cidade; da falta de manutenção das vias públicas, espaços abertos e propícios para a disseminação das moléstias; da ausência "de bons medicamentos, em que possa confiar", da "liberdade concedida a qualquer Cirurgião para curar de Medicina" e "da falta de vigilância sobre os Curandeiros, e Curandeiras e Boticários, que vend[iam] purgantes, vomitórios e outras composições sem receita de médico" (Silva, 1808, p.26). Esta última causa, aliás, permitia que "as lojas de ferragem" vendessem vomitórios, purgas, entre outros medicamentos (p.26). Em linhas gerais, para o físico-mor, um dos principais motivos que levavam as pessoas ao óbito na cidade do Rio de Janeiro era a falta de vigilância sobre os profissionais da saúde, que vendiam composições sem receita e em qualquer lugar, sem nenhum controle de tais atividades. Portanto, uma das intervenções que se faziam necessárias, segundo o físico-mor, era melhorar a regularização e a fiscalização na feitura e no comércio dos remédios.

O príncipe regente, muito provavelmente atendendo às solicitações feitas pelo físicomor, promulgou em 5 de novembro de 1808 um alvará sobre o exercício dos "boticários e a respeito do preço das drogas", solicitando, entre outras determinações, a elaboração de um regimento para "taxar o preço dos medicamentos e drogas" comercializados no Brasil (Brasil, 1891a, p.159). Esse alvará, além disso, determinava: (1) "que todos os Boticários" estavam "obrigados a vender seus medicamentos pelas taxas no Regimento determinadas, sem abatimento da terça parte, ou da metade da soma das receitas que o costume tem introduzido"; (2) "que em atenção à variedade dos preços das drogas medicinais, segundo a alternativa dos tempos, e do comércio, o dito Físico-mor proceda à reforma, em cada um dos anos, do dito Regimento, alterando os preços nesta conformidade"; (3) "que cada um dos boticários [tivesse] um exemplar do dito Regimento dos preços dos medicamentos para seu governo, assinado pelo sobredito Físico-mor e pelo boticário da ... real casa, e com as mesmas declarações, que já se mandou, e se tem praticado na Farmacopeia Geral, para que tenha o devido vigor"; (4) e, que todos os boticários estavam "obrigados a mostrar no Regimento a taxa dos medicamentos que venderem, a todas as pessoas [que] o quiserem ver", além de estar obrigados a preparar os remédios conforme as orientações da Farmacopeia geral para o Reino, e domínios de Portugal (Brasil, 1891a, p.159-160).

Publicada por ordem de dona Maria I, em 1794, a Farmacopeia geral... - a primeira farmacopeia oficial portuguesa - foi organizada por Francisco Tavares, médico da rainha e físico-mor, e tinha como principal objetivo uniformizar a composição e a preparação dos remédios em todo o reino português e seus domínios (Pita, 2000). Dividida em dois volumes, trazia, no primeiro, informações dos elementos da farmácia, com anotações que iam desde conhecimentos preliminares, como dos instrumentos utilizados, dos pesos e 
das medidas, até as regras gerais relativas à colheita dos símplices ou a alguma preparação. O segundo volume, por sua vez, voltava-se para a análise dos medicamentos símplices e compostos, com notas específicas de matéria farmacêutica, ou seja, do nome dos remédios, do lugar onde eram encontrados, da forma como se apresentavam, das finalidades e de suas respectivas propriedades. Em suma, essa primeira farmacopeia oficial portuguesa objetivava instruir todos aqueles que desejavam aprender a arte farmacêutica e, principalmente, tirar da "desordem, com que nas boticas" do reino e dos domínios de Portugal, como no Brasil, eram efetuadas as preparações e as composições dos medicamentos, tornando-se, pois, obrigatória (Tavares, 1794a).

Embora tenha se apresentado como a primeira farmacopeia oficial portuguesa, a Farmacopeia geral... não foi a única nem a primeira a ser produzida em Portugal e a circular no Brasil. No decorrer do século XVIII, muitas farmacopeias foram publicadas em território luso e, ainda que não fossem oficialmente reconhecidas, eram elas que guiavam os preparadores de remédios em Portugal e em suas colônias (Marques, 1999, p.71). Dos manuais de fabricação de medicamentos produzidos nessa época destacam-se: a Farmacopeia lusitana (1704), ${ }^{4}$ de autoria do cônego regular de Santo Agostinho e administrador da Real Botica de São Vicente de Fora, dom Caetano de Santo António, bem como todas as subsequentes edições reformadas e aumentadas de 1711, 1725 e 1754; ${ }^{5}$ o Coletâneo farmaceutico (1735), do boticário António Martins Sodré; a Farmacopeia bateana (1713), de George Bate; ${ }^{6}$ a Farmacopeia ulissiponense (1716), considerada o primeiro manual de química farmacêutica, em que eram ensinadas as preparações dos medicamentos químicos (Marques, 1999, p.72; Pita, 2000, p.188), de João Vigier; ${ }^{7}$ a Farmacopeia tubalense, do boticário Manoel Rodrigues Coelho, dividida em dois volumes, sendo o primeiro publicado em 1735 e o segundo apenas em 1751; a Farmacopeia portuense (1766), do cirurgião do Porto, António Rodrigues Portugal; ${ }^{8}$ a Farmacopeia dogmática (1772), do boticário beneditino frei João de Jesus Maria; ${ }^{9}$ e a Farmacopeia lisbonense (1785), ${ }^{10}$ de Manoel Joaquim Henriques de Paiva. ${ }^{11}$

A variedade e quantidade de farmacopeias produzidas no século XVIII em Portugal precedentes à Farmacopeia geral... indicam a necessidade de se formular uma farmacopeia oficial e também que tal publicação era igualmente tratada como um assunto de interesse público, isto é, o surgimento das farmacopeias pode ser considerado um movimento de reação dos médicos ilustrados contra os denominados segredistas, que vendiam por alto preço seus preparados secretos, sem que ninguém conhecesse suas composições. ${ }^{12}$ Era, portanto, uma forma de trazer ao conhecimento dos realizadores de medicamentos, as fórmulas e os conteúdos dos remédios (Silva, 2013, p.101). Além disso, todas essas obras surgem em um período notável na história da farmácia luso-brasileira, tanto pela introdução da química na preparação dos medicamentos quanto pelo aparecimento de um conjunto terapêutico cada vez mais enriquecido com os novos fármacos provenientes dos continentes descobertos pelos europeus, com especial ênfase para as drogas americanas. Tais novidades abriram espaço para que as farmacopeias se tornassem mais completas, mais rigorosas e, consequentemente, mais procuradas pelos produtores de remédios (Pita, 1999, p.55).

No Brasil, a exemplo do que ocorria em terras lusitanas, e sobretudo a partir da segunda metade do século XVIII, boa parte da feitura dos remédios seguia os princípios das farmacopeias portuguesas que por aqui circulavam (Silva, 2013, p.100; Marques, 
1999, p.77). Do mesmo modo, a partir de 1794, os homens envolvidos com a fabricação de remédios na América portuguesa também tiveram de substituir as antigas farmacopeias portuguesas, ou qualquer outro manual de preparação medicamentosa, pela Farmacopeia geral... Nesse sentido, a manipulação dos medicamentos, o exercício profissional do boticário e o funcionamento da botica, no reino português e em seus domínios, passavam a ser regulados e uniformizados pela farmacopeia oficial (Pita, 1999, p.63). Mais do que isso, a Farmacopeia geral... não era um simples livro de base para os preparadores de remédios, já que, mais do que impor determinadas prescrições à feitura dos remédios, buscava valorizar a farmácia enquanto ciência, ou seja, a própria arte de preparar os medicamentos passava a ser pensada como ciência (Pita, 1999, p.66).

Junto das farmacopeias portuguesas não oficiais produzidas no século XVIII, foi também muito comum, e isso desde pelo menos o final do século $\mathrm{XV}$, a existência de regimentos que taxavam o preço dos medicamentos. ${ }^{13} \mathrm{O}$ mais antigo deles de que se tem notícia é o Preços que pôs o doutor mestre Rodrigo às mezinhas nesta de Évora, sendo físico-mor, com consentimento dos vereadores; no ano de Cristo Nosso Senhor de 1497. Essa obra, além de trazer informações de uma série de remédios usados naquele tempo - como os diversos tipos de águas curativas (água de hortelã, água de marmelos, água rosada, entre outras) e de conservas (conserva de viola, de abóbora, de laranja etc.) - e de seus respectivos pesos e medidas - que iam de uma a 40 onças -, dá mostras de que, pelo menos até o final do século XVI, a taxa dos remédios em Portugal estava sob o domínio municipal, uma vez que o documento tinha sido aprovado pelos vereadores da Câmara (Silva, 1868, p.70).

Nos séculos XVII e XVIII, entretanto, foram impressos oito regimentos de taxas de medicamentos em Portugal, e, ao contrário do citado regimento de Évora, as taxações agora eram previstas para todo o território português, inclusive seus domínios. ${ }^{14}$ Além disso, todos eles, conforme a indicação de seus respectivos títulos, foram elaborados pelos físicos-mores de cada época, mas nenhum, ao que parece, considerou o conteúdo das farmacopeias portuguesas não oficiais, melhor dizendo, tais regimentos dos preços eram elaborados simplesmente segundo a opção de quem os realizava, sem qualquer padronização aparente. Nesse sentido, o primeiro regulamento de taxação de remédios consoante ao conteúdo de uma farmacopeia foi publicado somente depois da Farmacopeia geral..., trata-se do Regimento dos preços dos medicamentos símplices, preparados e compostos, assim como se descrevem na Farmacopeia Geral do Reino, feito e publicado por ordem de Sua Alteza Real, o príncipe regente, nosso senhor, para governo dos boticários de seus reinos no ano de 1804 (Tavares, 1804).

Apesar de esse Regimento dos preços dos medicamentos..., de 1804, ter sido impresso pela primeira vez dez anos depois da primeira farmacopeia portuguesa oficial, a autorização para a sua confecção data do início de $1795 .{ }^{15}$ Segundo o conteúdo do alvará de 3 de março de 1795, a produção de um regimento dos preços fazia-se necessária "para obviar os prejuízos e danos, que da falta" de um regulamento desse tipo poderia trazer à real fazenda da rainha e de seus vassalos, e também porque, de acordo com um "antigo costume", os preços dos medicamentos deveriam ser "regulados de três em três anos", o que já não acontecia há um bom tempo (Portugal, 1828, p.209). Os responsáveis por taxar "o preço das drogas e dos medicamentos para regra dos boticários" do reino foram o autor da farmacopeia oficial, Francisco Tavares, e três dos considerados mais inteligentes boticários do reino. 
Desse modo, o aparecimento do Regimento dos preços dos medicamentos..., em 1804, quase que simultaneamente à publicação da farmacopeia oficial, é indício de que ele era um importante instrumento a fim de organizar a farmácia e sua prática em Portugal entre o final do século XVIII e início do XIX.

Tal regimento dos preços, no entanto, dizia respeito somente aos remédios comercializados em Portugal, ou seja, ao contrário da Farmacopeia geral..., ele não era destinado, por exemplo, aos realizadores de remédios na América portuguesa. No Brasil, a elaboração de uma taxa de medicamentos para uso dos boticários ocorreu apenas depois do alvará de 5 de novembro de 1808. ${ }^{16}$ Publicado pela primeira vez em $1809,{ }^{17}$ o Regimento dos preços dos medicamentos símplices, preparados e compostos, assim como se descrevem na Farmacopeia geral do Reino, feito e publicado por ordem de Sua Alteza Real, o príncipe regente, nosso senhor, para governo dos boticários nos estados do Brasil é constituído por uma folha de rosto, pela transcrição integral do texto da lei que autorizou a sua criação e por mais 35 páginas que estampam o nome dos medicamentos e suas respectivas taxas.

Os remédios e seus respectivos preços aparecem dispostos em ordem alfabética e divididos em três categorias: "taxa dos medicamentos símplices"; "taxa dos medicamentos preparados, e compostos"; e "taxa das preparações, e composições dos medicamentos em si mesmas" (Silva, 1809, p.9, 23 e 43). Vale destacar que, no contexto desse regimento, os medicamentos símplices são os que "a natureza ministra, e que se aplicam tais, quais existem; ou aqueles que levam preparações muito ligeiras", e os medicamentos compostos são "os que resultam da mistura das drogas simples" (Pinto, 1805, p.22). Já a última categoria era sobre as taxas das atividades dos boticários, ou seja, era uma taxa para custear a mão de obra do profissional, e informava, por exemplo, quanto custava "fazer a mistura de cada onça de pós compostos", "pratear cada onça de pílulas", "cada libra de qualquer líquido destilado", entre outros preparos e composições (Silva, 1809, p.43-44).

Como os medicamentos podiam se apresentar na forma líquida ou sólida, as taxas no Regimento dos preços dos medicamentos... determinavam as suas quantidades baseando-se em pesos e medidas. Os remédios sólidos tinham suas taxas estabelecidas a partir dos pesos calculados em grão, oitava, onça ou libra. O grão era "igual ao peso que tem um grão de trigo, ou de cevada", a oitava, equivalia a três escrópulos, sendo que cada escrópulo correspondia a 24 grãos, a onça, por sua vez, "constava de oito oitavas", e a libra medicinal, que diferentemente da libra civil ou mercantil - de 16 onças -, correspondia a 12 onças. Já os medicamentos líquidos calculavam as suas medidas em onça ou libra, cuja correspondência era de oito oitavas e 12 onças e, por conseguinte, tinham suas taxas definidas (Tavares, 1794a, p.7-10).

Mais do que os preços e a maneira como os remédios eram medidos e pesados, esse regulamento contém uma grande seleção dos medicamentos frequentemente utilizados naquele tempo. Para se ter uma ideia, são mais de oito centenas de taxas, sendo 373 de medicamentos símplices, 435 de medicamentos compostos e 20 de preparações e composições. Uma parte dos remédios contidos no Regimento dos preços dos medicamentos..., aliás, era proveniente da flora brasileira ou nela já eram cultivados, a saber: a abutua, a almecega-do-Brasil em pó, o bálsamo, ou óleo de copaíba, a jalapa, a ipecacuanha, a quina, o sarro de vinho, ${ }^{18}$ entre outros. A descrição dessa variedade de medicamentos, bem como 
os preços pelos quais eram comercializados os símplices e compostos listados no Regimento dos preços dos medicamentos..., entretanto, não são o objetivo deste texto. O propósito, aqui, é um tanto mais modesto, mas não menos importante: lançar luz sobre um documento que, segundo os indícios da época, parece ter sido um instrumento fundamental na organização da farmácia e no estabelecimento do exercício profissional dos homens envolvidos com a manipulação de remédios no Brasil no início do século XIX. Em outras palavras, a principal intenção desta pequena introdução é situar historicamente uma obra pouco conhecida, mas extremamente significativa para a regulamentação da farmácia brasileira oitocentista.

A inédita transcrição e edição do Regimento dos preços dos medicamentos símplices, preparados e compostos, assim como se descrevem na Farmacopeia Geral do Reino, feito e publicado por ordem de Sua Alteza Real, o príncipe regente, nosso senhor, para governo dos boticários nos estados do Brasil, apresentada a seguir, baseou-se no primeiro e único exemplar de 1809, conservado sob a guarda da Biblioteca Nacional do Rio de Janeiro, ${ }^{19}$ e na edição de 1818 , disponível para download na internet graças à digitalização da US National Library of Medicine. Além disso, no intuito de facilitar a compreensão do texto e tornar mais claro o seu conteúdo, o texto passou por atualização na linguagem e na pontuação, conforme a norma culta da língua portuguesa.

\section{AGRADECIMENTOS}

A autora integra o projeto temático "Escritos sobre os novos mundos: uma história da construção de valores morais em Língua Portuguesa", financiado pela Fundação de Amparo à Pesquisa do Estado de São Paulo (Fapesp), processo n.13/14786-6. O presente trabalho contou com financiamento do programa de Aides spécifiques da Casa de Velázquez: Écoles Françaises à l'Étranger.

\section{NOTAS}

${ }^{1}$ Nascido em Ourém, Portugal, em 11 de novembro de 1753, Manoel Vieira da Silva formou-se em medicina pela Universidade de Coimbra e veio para o Brasil acompanhando a família real. Foi provedor-mor da Saúde e, depois, físico-mor do Reino. Faleceu em 17 de novembro de 1826, na aldeia da Cruz, em Portugal (Ribeiro, 1992, p.21).

${ }^{2}$ Segundo Pimenta (1997, p. 22), apesar de "os cargos de físico-mor e cirurgião-mor" e, consequentemente, a Fisicatura-mor, terem sido recriados em 7 de fevereiro de 1808, a Junta do Protomedicato vigorou em Portugal e só foi extinta quase um ano depois, em 7 de janeiro de 1809.

${ }^{3}$ José Correia Picanço nasceu na cidade de Goiana, na capitania de Pernambuco, e era filho do cirurgiãobarbeiro Francisco Correia Picanço. Formou-se em medicina pela Universidade de Paris e depois, em 1789, foi convidado para ser lente na Universidade de Coimbra, onde ficou até retornar ao Brasil junto com a família real portuguesa, em 1808 (Gomes, 1951).

${ }^{4}$ Segundo o estudioso da farmácia portuguesa João Rui Pita (2000, p.161), "assiste-se em Portugal", no início do século XVIII, "a uma afirmação da farmácia conventual". Por essa época, diversos mosteiros e conventos, bem como religiosos de várias ordens, desempenharam um papel de valor na farmácia de Portugal. Ficaram famosas, por exemplo, as boticas dos cônegos regrantes de Santo Agostinho, dos dominicanos e dos padres da Companhia de Jesus. Era de esperar, portanto, que a primeira farmacopeia portuguesa, ainda que não oficial, fosse resultado de uma dessas ordens religiosas.

${ }^{5}$ A Farmacopeia lusitana de dom Caetano de Santo António teve quatro edições, sendo todas elas publicadas na primeira metade do século XVIII, sempre com alguma mudança em relação à edição anterior. Na edição de 1711, para se ter uma ideia, a Farmacopeia lusitana reformada introduziu "algumas fórmulas de substâncias químicas", bem como "medicamentos preparados com plantas brasílicas, tal como a salsaparrilha" (Marques, 1999, p.72; Dias, 1990, p.46)

${ }^{6}$ Em Portugal, a Farmacopeia bateana foi traduzida do latim por dom Caetano de Santo António e publicada pela primeira vez em 1713. Segundo indicou o pesquisador português João Rui Pita (1999, p.52), o tradutor 
dessa obra assegurava que "era urgente a divulgação em língua portuguesa daquele texto para que a utilização e o acesso à produção de determinados medicamentos fossem mais fáceis".

${ }^{7}$ Um boticário francês que vivia em Portugal desde a segunda metade do século XVII.

${ }^{8}$ A Farmacopeia portuense, conforme a nota de apresentação de António Rodrigues Portugal (1766), buscava complementar o conteúdo das demais farmacopeias utilizadas em Portugal, pois, seu principal objetivo era fornecer "muitas das composições que estão mais em uso, e se não acham nas nossas farmacopeias portuguesas", informações essas, aliás, retiradas dos manuais de fabricação de remédios de Londres, Edimburgo, Paris, entre outros.

${ }^{9}$ A Farmacopeia dogmática, do monge beneditino frei João de Jesus Maria, foi publicada em dois tomos; a primeira parte trata especificamente das operações farmacêuticas e composições, enquanto a segunda aborda os usos dos animais, dos vegetais e dos minerais na preparação dos medicamentos (Exposição..., 1972, p.17).

${ }^{10}$ Segundo Marques (1999, p.76), Henriques de Paiva publicou a Farmacopeia lisbonense porque estava muito impaciente "com a demora com que se preparavam uma farmacopeia oficial" e tentou, assim, "dar sua contribuição na busca de dirimir a realidade funesta de ver tantos medicamentos sendo "mal preparados por diversos métodos e fórmulas".

${ }^{11}$ Manoel Joaquim Henriques de Paiva foi médico e boticário em Portugal e depois se transferiu para o Brasil e ocupou a cadeira de farmácia, matéria médica e terapêutica na Academia Médico-cirúrgica da Bahia, em 1824.

${ }^{12}$ Segundo João Rui Pita (1999, p.57; destaque no original), a publicação de farmacopeias não oficiais, entre 1704 e 1794, se deu pela necessidade de "normalizar o conhecimento dos 'símplices' e de se definirem regras claras para a produção e conservação medicamentosa". Na verdade, continua Pita, essas farmacopeias pretendiam dar a "conhecer algumas das fórmulas mais recentes e mais utilizadas no estrangeiro e divulgar, pelas comunidades médica e farmacêutica, os mais atualizados conceitos relativos aos medicamentos e à produção medicamentosa".

${ }^{13}$ Sobre os regimentos dos preços dos medicamentos publicados em Portugal destaca-se o estudo de Pedro José da Silva (1868, p.70-104), no qual o autor fez uma relação de todos os regimentos que ele encontrou e que foram publicados entre os séculos XV e XIX.

${ }^{14}$ Os oito regimentos de preços publicados entre os séculos XVII e XVIII são: Regimento dos preços, por onde os boticários hão de vender as suas mezinhas..., de 1653; Regimento dos preços, por que os boticários devem vender as suas drogas..., de 1676; Regimento dos preços, por que os boticários hão de vender suas medicinas, de 1696; Regimento dos preços para os boticários venderem as medicinas..., de 1761; Regimento dos preços para os boticários venderem as medicinas..., de 1764; Regimento dos preços para os boticários venderem as medicinas..., de 1767; Regimento dos preços para os boticários venderem as medicinas..., de 1770; Regimento dos preços, pelos quais os boticários devem vender os medicamentos, que lhes forem receitados para curativo dos doentes unicamente..., de 1789 (Silva, 1868, p.74).

${ }^{15} \mathrm{O}$ Suplemento à Coleção da Legislação Portuguesa traz uma compilação do Regimento dos preços dos medicamentos aprovados pelo alvará de 3 de março de 1795; todavia, como se trata de uma compilação, e por não haver nenhuma menção a qualquer exemplar desse regimento, consideramos que a primeira impressão do Regimento dos preços de medicamentos..., consoante aos medicamentos da Farmacopeia geral..., ocorreu em 1804. Para mais informação, ver Portugal (1847, p.58-83) e Silva (1868, p.75).

${ }^{16}$ Há de se notar a existência do Regimento, que devem observar os comissários delegados do físico-mor do Reino no estado do Brasil, de 1744, cujo principal objetivo era intensificar a fiscalização do exercício das artes de curar na colônia e coibir os abusos que ocorriam no preparo e na venda dos medicamentos, uma vez que, por esse tempo, havia grande disputa entre os boticários e os demais mercadores em relação à competência da venda dos remédios. Essa lei, pois, buscava regrar o exercício do profissional da botica, mas não versava acerca dos preços praticados no comércio dos medicamentos (Marques, 1999, p.183-184). Além disso, tal documento caiu em desuso com a extinção do cargo de cirurgião-mor, em 1782, deixando a cargo da Junta do Protomedicato a fiscalização da prática médica, além da concessão de cartas de exercício profissional e do controle de hospitais civis e militares (Silva, 2013, p.93).

${ }^{17}$ Como o alvará de 5 de novembro de 1808 previa que as taxas dos medicamentos fossem atualizadas de três em três anos, temos notícia de que esse regulamento foi publicado em 1809, 1811, 1813, 1818 e 1820 , até onde foi possível observar (Camargo, Moraes, 1993, p.34).

${ }^{18}$ Sobre esses remédios, consultar Tavares (1794b, p.7, 13, 18, 42, 65, 90, 91, 102).

${ }^{19}$ Esse exemplar do Regimento dos preços dos medicamentos..., de 1809, encontra-se no Acervo de Livros Raros (código de localização: 037,002,022). 


\section{REFERÊNCIAS}

ABREU, Jean Luiz Neves.

Nos domínios do corpo: o saber médico lusobrasileiro no século XVIII. Rio de Janeiro: Editora Fiocruz. 2011.

ANÚNCIOS.

Anúncios. Gazeta do Rio de Janeiro, n.32, p.4. 31 dez. 1809.

ARAÚJO, Carlos da Silva.

Fatos e personagens da história da medicina e da farmácia no Brasil. v.1. Rio de Janeiro: Continente. 1979.

BRASIL.

Alvará de 5 de novembro de 1808. Dá várias providências sobre os boticários e a respeito dos preços das drogas. Coleção das leis do Brasil de 1808. Rio de Janeiro: Imprensa Nacional. p.159161. 1891a.

BRASIL.

Alvará de 23 de novembro de 1808. Manda executar os Regimentos de Físico Mor e Cirurgião Mor e regula a sua jurisdição e de seus Delegados. In: Coleção das leis do Brasil de 1808. Rio de Janeiro: Imprensa Nacional. p.163-164. 1891b.

CAMARGO, Ana Maria de Almeida; MORAES, Rubens Borba de.

Bibliografia da Impressão Régia do Rio de Janeiro. v.1. São Paulo: Edusp; Kosmos. 1993.

DIAS, José Pedro Sousa.

Literatura farmacêutica portuguesa do século XVIII (1690-1815). In: Dias, José Pedro Sousa (Coord.). A farmácia setecentista: uma introdução à história, literatura e cerâmica da farmácia em Portugal no século XVIII. Lisboa: Biblioteca Nacional de Lisboa. 1990.

EXPOSIÇÃO...

Exposição de obras antigas e revistas portuguesas de farmácia. XXXII Congresso Internacional de Ciências Farmacêuticas. Lisboa: Biblioteca Nacional de Lisboa. 1972.

GOMES, Ordival Cassiano.

Fundação do ensino médico no Brasil. José Correia Picanço. Revista de História, v.3, n.7, p.143-172. 1951.

MARQUES, Vera Regina Beltrão.

Natureza em boiões: medicinas e boticários no Brasil setecentista. Campinas: Editora da Unicamp/Centro de Memória-Unicamp. 1999.

PIMENTA, Tânia Salgado.

Entre sangradores e doutores: práticas e formação médica na primeira metade do século XIX. Caderno Cedes, v.23, n.59, p.91-102. 2003.
PIMENTA, Tânia Salgado.

Artes de curar: um estudo a partir dos documentos da Fisicatura-mor no Brasil do começo do século XIX. Dissertação (Mestrado em História) - Instituto de Filosofia e Ciências Humanas, Universidade Estadual de Campinas, Campinas. 1997.

PINTO, Antonio José de Sousa.

Elementos de farmácia, química, e botânica, para uso dos principiantes, dedicados ao muito alto $e$ soberano príncipe regente D. João nosso senhor por Antonio José de Sousa Pinto, boticário nesta Corte. Lisboa: Impressão Régia. 1805.

PITA, João Rui.

História da farmácia. Coimbra: Minerva. 2000.

PITA, João Rui.

Um livro com 200 anos: a Farmacopeia

Portuguesa (edição oficial): a publicação da primeira farmacopeia oficial: Pharmacopeia Geral (1794). Revista de História das Ideias, v.20, p.47-100. 1999.

PORTUGAL, António Rodrigues.

Farmacopeia portuense... Porto: Francisco Mendes Lima. 1766.

PORTUGAL

Regimento dos preços dos medicamentos aprovados pelo alvará de 3 de março de 1795 . In: Suplemento à Coleção da Legislação Portuguesa do desembargador Antonio Delgado da Silva. Pelo mesmo ano de 1791 a 1820. Lisboa: Tipografia de Luiz Correia da Cunha. 1847.

PORTUGAL.

Alvará de 3 de março de 1795 . Alvará mandando observar o Regimento dos preços dos medicamentos; e providenciando sobre o mesmo objeto. In: Coleção da Legislatura Portuguesa, desde a última compilação das ordenações, pelo desembargador Antonio Delgado da Silva. Legislação 1791 a 1801. Lisboa: Tipografia Maigrense. 1828.

RIBEIRO, Lourival.

O barão do Lavradio e a higiene no Rio de Janeiro. Belo Horizonte: Itatiaia. 1992.

RIBEIRO, Márcia Moisés.

A ciência dos trópicos: a arte médica no Brasil do século XVIII. São Paulo: Hucitec. 1997.

SCHWARCZ, Lilia Moritz; AZEVEDO, Paulo Cesar de; COSTA, Angela Marques da.

A longa viagem da biblioteca dos reis: do terremoto de Lisboa à independência do Brasil. São Paulo: Companhia das Letras. 2002.

SILVA, Manoel Vieira da.

Regimento dos preços dos medicamentos símplices, preparados e compostos, assim como se descrevem 
na Farmacopeia Geral do Reino, feito e publicado por ordem de Sua Alteza Real, o príncipe regente, nosso senhor, para governo dos boticários nos estados do Brasil. Rio de Janeiro: Impressão Régia. 1809.

SILVA, Manoel Vieira da.

Reflexões sobre alguns dos meios propostos por mais conducentes para melhorar o clima da cidade do Rio de Janeiro. Rio de Janeiro: Impressão Régia. 1808.

SILVA, Maria Beatriz Nizza da.

Cultura letrada e cultura oral no Rio de Janeiro dos vice-reis. São Paulo: Editora Unesp. 2013.

SILVA, Pedro José da.

História da farmácia portuguesa desde os primeiros séculos da monarquia até ao presente. Lisboa: [s.n.] 1868
TAVARES, Francisco.

Regimento dos preços dos medicamentos símplices, preparados e compostos, assim como se descrevem na Farmacopeia Geral do Reino, feito e publicado por ordem de sua alteza real, o príncipe regente, nosso senhor para governo dos boticários de seus reinos no ano de 1804. Lisboa: Impressão Régia. 1804.

TAVARES, Francisco.

Farmacopeia geral para o Reino, e domínios de Portugal publicada por ordem da rainha fidelíssima D. Maria I. t.1: Elementos de farmácia. Lisboa: Régia Oficina Tipográfica. 1794a.

TAVARES, Francisco.

Farmacopeia geral para o Reino, e domínios de Portugal publicada por ordem da rainha fidelíssima D. Maria I. t.2: Medicamentos símplices, preparados e compostos. Lisboa: Régia Oficina Tipográfica. 1794b.

\section{$\rightarrow \rightarrow \rightarrow<<$}




\title{
REGIMENTO DOS PREÇOS DOS MEDICAMENTOS SÍMPLICES, PREPARADOS E COMPOSTOS, ASSIM COMO SE DESCREVEM NA FARMACOPEIA GERAL DO REINO, FEITO E PUBLICADO POR ORDEM DE SUA ALTEZA REAL O PRÍNCIPE REGENTE, NOSSO SENHOR, PARA GOVERNO DOS BOTICÁRIOS NOS ESTADOS DO BRASIL.
}

\author{
ANO DE 1809. \\ RIO DE JANEIRO. \\ NA IMPRESSÃO RÉGIA.
}

Eu, o Príncipe Regente, faço saber aos que este alvará virem, que tendo eu atendido ao importantíssimo objeto da saúde dos meus fiéis vassalos, e tendo sido publicada, pelo alvará de sete de janeiro de mil setecentos e noventa e quatro, a Farmacopeia Geral, para que nos meus reinos e domínios fosse uniforme a preparação e composição dos medicamentos, e, deste modo, se prevenissem e evitassem os descuidos, enganos e faltas da necessária cautela em tão interessante artigo, e havendo já decorrido longo tempo, sem que se regulassem os preços dos medicamentos nestes estados do Brasil, e havendo na Farmacopeia Geral do Reino uma regra fixa, e já autorizada, a fim de se fazer com toda a segurança um semelhante regulamento para obviar os prejuízos, e danos, que da falta do Regimento de preços dos remédios resultam à minha fazenda e à dos meus vassalos, houve por bem do meu real serviço encarregar ao Doutor Manoel Vieira da Silva, do meu conselho, e físico-mor do reino, que conferindo com dois boticários dos mais inteligentes, e próprios, quais ele nomeasse, procedesse a taxar o preço dos medicamentos e drogas para regra dos boticários. E sendome presente o dito Regimento por ele ordenado e achando que é segundo as minhas reais intenções e determinações, sou servido mandar a este respeito o seguinte:

I. Que todos os boticários de meus reinos sejam obrigados a vender seus medicamentos pelas taxas no Regimento determinadas, sem abatimento de terça parte, ou da metade da soma das receitas que o costume tem introduzido por circunstâncias que presentemente não ocorrem. E por quanto desta quase necessidade de fazer semelhantes abatimentos podem facilmente originar-se abusos de substituições dolosas e danosas à saúde de meus vassalos, e cometer-se faltas essenciais nas composições dos remédios, faço por abolido este costume, e mando aos julgadores e justiças de meus reinos, que nos casos da sua competência assim mesmo julguem, e façam executar da publicação deste alvará em diante conforme o tempo, e era declarada no Regimento, condenando aos boticários, que tais abatimentos fizerem, no dobro da importância dos ditos abatimentos, a metade para o acusador e outra metade 
para o hospital mais vizinho, em razão da má-fé, que destes abatimentos de soma se deve presumir, sendo como são os preços racionalmente taxados.

II. Que em atenção à variedade dos preços das drogas medicinais segundo a alternativa dos tempos e do comércio, o dito físico-mor proceda à reforma em cada um dos anos do dito Regimento, alterando os preços nesta conformidade, e da mesma maneira, que lhe foi determinado, enquanto eu não for servido mandar o contrário; e não publicando, porém, a reforma sem prévia licença minha.

III. Que cada um dos boticários tenha um exemplar do dito Regimento dos preços dos medicamentos para seu governo, assinado pelo sobredito físico-mor, e pelo boticário da minha real casa, da mesma forma, e com as mesmas declarações, que já se mandou, e se tem praticado na Farmacopeia Geral para que tenha o devido vigor, e que no frontispício dele se declare a era a que pertence, para regular as somas das receitas do tempo, que lhe for correspondente. E que nas visitas das boticas se inquira quanto sobre este particular se julgar necessário; e das faltas se tome conhecimento para se imporem aos delinquentes as penas que em outro lugar estão determinadas.

IV. Que em advertências relativas ao modo de algumas somas de medicamentos, que no mesmo Regimento não vão declaradas, se observem, como nelas se contém, e que este alvará, e ditas advertências se reimprimam nos exemplares do Regimento que mando formar em cada ano.

V. Que os boticários do interior destes estados, por isso que ficam em grandes distâncias dos portos do mar, e em razão de transportar por terra os medicamentos, lhes chegam muito mais caros, serão obrigados a pedir pelos medicamentos mais uma quinta parte dos preços determinados neste Regimento, ficando sujeitos às mesmas penas já determinadas.

VI. Serão os boticários obrigados a mostrar, no Regimento a taxa dos medicamentos que venderem, a todas as pessoas que o quiserem ver e assim lhe requererem.

Pelo que mando à Mesa do Desembargo do Paço, e da Consciência e Ordens; ao Presidente de Meu Real Erário; ao Regedor da Casa da Suplicação do Brasil; ao Governador da Relação da Bahia; aos Governadores e Capitães Generais, e mais Governadores do Brasil, e dos meus Domínios Ultramarinos; e a todos os ministros de Justiça, e mais pessoas, a quem pertencer o conhecimento e execução deste alvará, que o cumpram, guardem e façam inteiramente cumprir e guardar, como nele se contém, não obstante, quaisquer leis, alvarás, regimentos, decretos, ou ordens em contrário, porque todos e todas faço por derrogadas para este feito somente, como se delas fizesse expressa, e individual menção, ficando aliás sempre em seu vigor. E este valerá como carta passada pela chancelaria, ainda que por ela não há de passar, e que o seu efeito haja de durar mais de um ano, sem embargo da Ordenação em contrário; registrando-se em todos os lugares, onde se costumam registrar semelhantes alvarás. Dado no palácio do Rio de Janeiro em cinco de novembro de mil oitocentos e oito.

\section{PRÍNCIPE}

\section{Fernando José de Portugal.}

Alvará pelo qual Vossa Alteza Real há por bem determinar várias providências sobre os boticários e sobre os preços das drogas; na forma acima exposta. 
Para a Vossa Alteza Real ver.

Joaquim Antonio Lopes da Costa o fez.

Registrado nesta Secretaria de Estado dos Negócios do Brasil no livro primeiro de leis, alvarás, e cartas régias a folhas sessenta e seis. Rio de Janeiro em onze de novembro de mil e oitocentos e oito.

João Baptista de Alvarenga Pimentel.

\section{ADVERTÊNCIAS}

A que se refere o Alvará no $§ I V$.

I. Os medicamentos símplices que no Regimento não forem taxados, se reputarão com a adição de mais a terça parte do seu custo real nas drogarias por libra civil, deduzindo-se as quantidades menores reguladas pelo dito preço aplicado à libra médica.

II. As preparações e composições dos remédios, que se aviarem por fórmulas magistrais, se farão segundo a taxa, que em seu lugar se determina, independente do custo dos medicamentos símplices, de que constarem.

\begin{tabular}{|c|c|c|c|c|}
\hline \multicolumn{5}{|c|}{ A } \\
\hline Nome do medicamento & Libra & Onça & Oitava & Grão \\
\hline Abutua (raiz) & & 10 & & \\
\hline Abutua em pó & & 40 & 15 & \\
\hline Açafrão (em rama) & & 1600 & 220 & \\
\hline Açafrão em pó & & 1800 & 300 & \\
\hline Acônito (folhas) & & 60 & & \\
\hline Acônito em pó & & 120 & 20 & \\
\hline Agriões & & 10 & 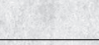 & 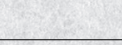 \\
\hline Alambre (em sorte) & & 100 & 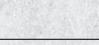 & 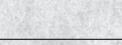 \\
\hline Alambre em pó & E & 160 & 30 & 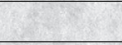 \\
\hline Alcaçuz (raiz) & & 30 & & 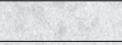 \\
\hline Alcaçuz em pó & & 80 & 15 & + \\
\hline Alcanfor (em sorte) & & 480 & 80 & 5 \\
\hline Alcanfor em pó & & 560 & 100 & 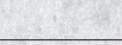 \\
\hline Alcatira (em sorte) & & 120 & 20 & \\
\hline Alcatira em pó & & 160 & 40 & 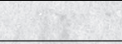 \\
\hline Alecrim (folhas) & & 20 & +2 & 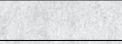 \\
\hline Alecrim flores & & 120 & 20 & \\
\hline Alexandria (semente) & & 120 & & + \\
\hline Alexandria em pó & & 160 & 40 & 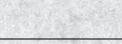 \\
\hline Alfazema & & 20 & & 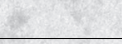 \\
\hline Alho & & 20 & & 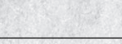 \\
\hline Almecega da Índia (em sorte) & & 120 & & \\
\hline
\end{tabular}




\section{TAXA DOS MEDICAMENTOS SÍMPLICES}

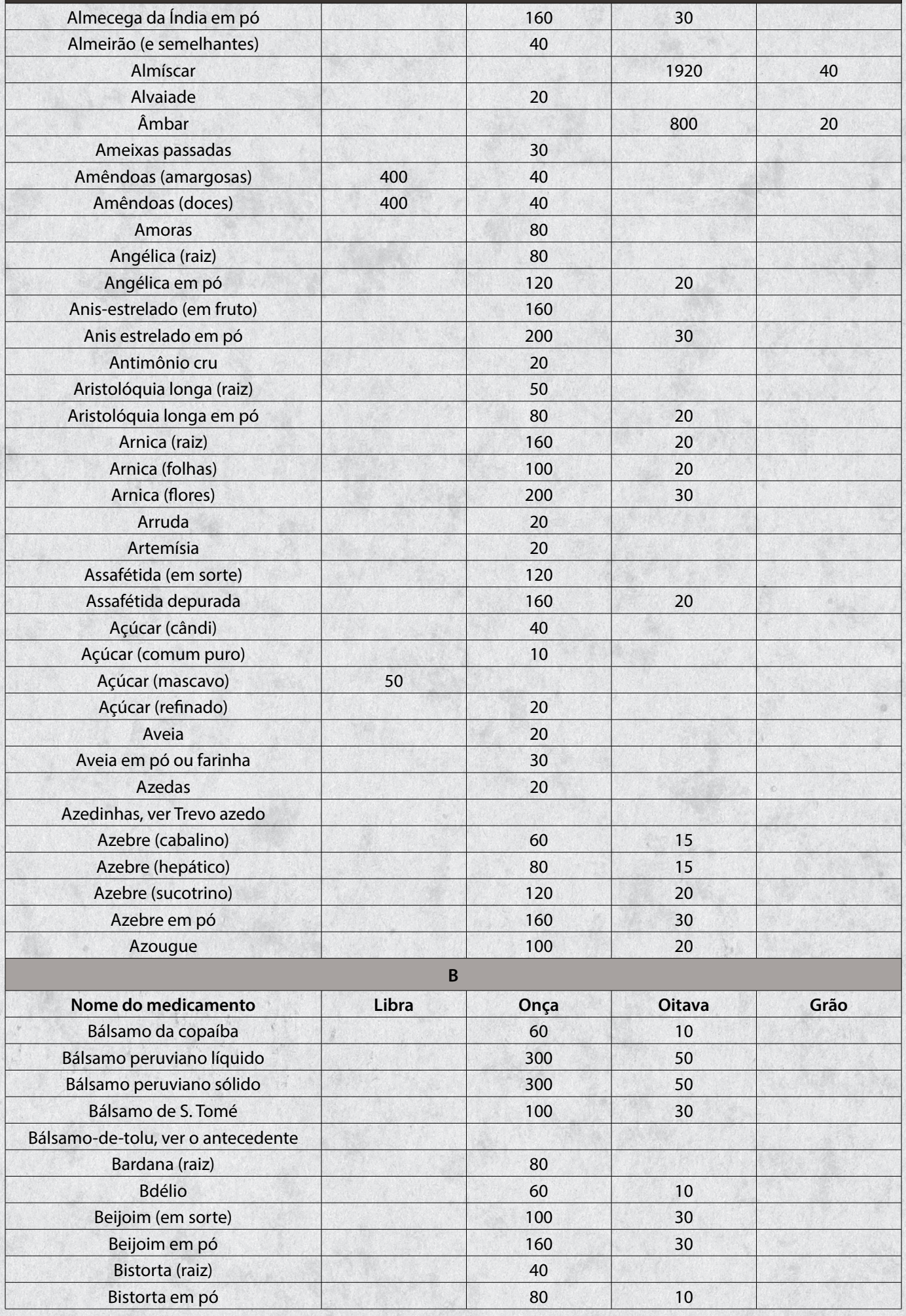




\section{TAXA DOS MEDICAMENTOS SÍMPLICES}

\begin{tabular}{|c|c|c|c|c|}
\hline Bolo & & 20 & & \\
\hline Bórax, ver Trincal & & & & - \\
\hline \multicolumn{5}{|c|}{ C } \\
\hline Nome do medicamento & Libra & Onça & Oitava & Grão \\
\hline Cal virgem & 100 & & & \\
\hline Cálamo-aromático (raiz) & & 80 & & 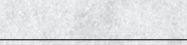 \\
\hline Cálamo-aromático em pó & & 120 & 20 & 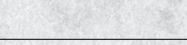 \\
\hline Calumba (raiz) & & 100 & 15 & \\
\hline Calumba em pó & & 140 & 25 & \\
\hline Camédrios & & 60 & 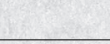 & \\
\hline \multicolumn{5}{|l|}{ Cânfora, ver Alcanfor } \\
\hline Canafístula & & 60 & & \\
\hline Canela fina (casca) & & 200 & + & \\
\hline Canela fina em pó & & 280 & 40 & \\
\hline Cantáridas & & 1600 & 240 & 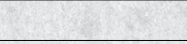 \\
\hline Cantáridas em pó & & 1680 & 260 & 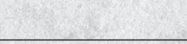 \\
\hline \multicolumn{5}{|l|}{ Caparrosa azul, ver Vitríolo de cobre } \\
\hline \multicolumn{5}{|c|}{$\begin{array}{c}\text { Caparrosa branca, ver Vitríolo branco, } \\
\text { ou de zinco }\end{array}$} \\
\hline \multicolumn{5}{|c|}{ Caparrosa verde, ver Vitríolo de ferro } \\
\hline Cardamomo menor (fruto) & & 320 & + & \\
\hline Cardamomo menor (em pó) & & 400 & 60 & \\
\hline Cardo-santo (folhas) & & 40 & & (1) \\
\hline Cardo-santo em pó & 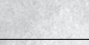 & & 20 & \\
\hline \multicolumn{5}{|l|}{ Carrapatos, ver Mamona } \\
\hline Cascarrilha (casca) & 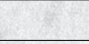 & 160 & & \\
\hline Cascarrilha em pó & & & 30 & \\
\hline Castóreo (em sorte) & & 600 & & \\
\hline Castóreo em pó & & 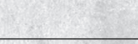 & 100 & 5 \\
\hline Cato em sorte & & 80 & & \\
\hline Cato em pó & & 100 & 20 & \\
\hline Cebola albarrã & & 40 & & \\
\hline Cebola seca & & 60 & 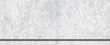 & \\
\hline Cebola pó & & 80 & & 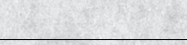 \\
\hline Celidônia (raiz) & & 40 & & 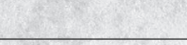 \\
\hline Celidônia erva & & 40 & & +2 \\
\hline Centáurea-menor & & 60 & & 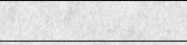 \\
\hline Cera amarela & 600 & 50 & & \\
\hline Cera branca & 800 & 60 & & 8 \\
\hline Cerofólio & & 80 & & \\
\hline \multicolumn{5}{|l|}{ Cerfolho, ver o antecedente } \\
\hline Cevada & & 10 & & S \\
\hline Cevada descascada & & 20 & & 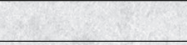 \\
\hline Cicuta (folhas) & & 60 & & 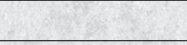 \\
\hline Cicuta em pó & & 100 & 20 & \\
\hline Cipó, ver Ipecacuanha & & & & + \\
\hline Cocleária & & 100 & & \\
\hline Colchicum (raiz rec.) & & 40 & & \\
\hline Colchicum em pó & 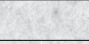 & 60 & & \\
\hline
\end{tabular}


TAXA DOS MEDICAMENTOS SÍMPLICES

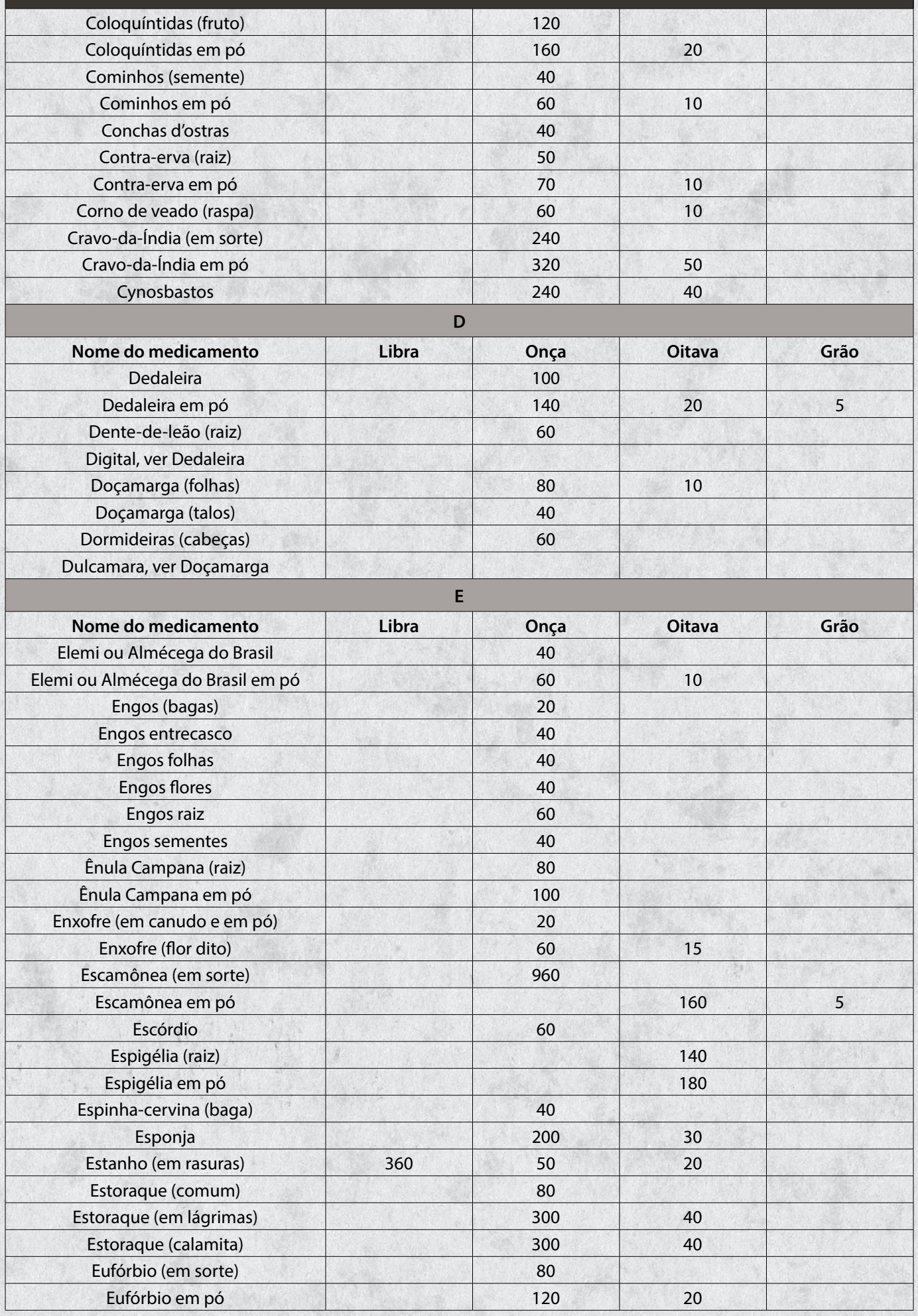


TAXA DOS MEDICAMENTOS SÍMPLICES

\begin{tabular}{|c|c|c|c|c|}
\hline \multicolumn{5}{|c|}{$\mathbf{F}$} \\
\hline Nome do medicamento & Libra & Onça & Oitava & Grão \\
\hline \multicolumn{5}{|l|}{ Fel da terra, ver Centáurea-menor } \\
\hline Ferro (em limalha) & 80 & & 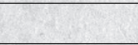 & \\
\hline Fezes de ouro & & 20 & & \\
\hline \multicolumn{5}{|l|}{ Flor de noz-moscada } \\
\hline Fumária & & 80 & +2 & - \\
\hline Funcho (erva) & 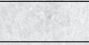 & 20 & 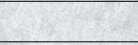 & \\
\hline Funcho (sementes) & & 60 & & \\
\hline Funcho (raiz) & & 40 & & \\
\hline \multicolumn{5}{|c|}{ G } \\
\hline Nome do medicamento & Libra & Onça & Oitava & Grão \\
\hline Gálbano & & 120 & B & \\
\hline Galhas & & 60 & & 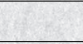 \\
\hline Galhas em pó & & 80 & 15 & 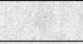 \\
\hline Genciana (raiz) & & 60 & & 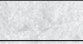 \\
\hline Genciana em pó & & 80 & 15 & \\
\hline Gengibre (raiz) & & 50 & 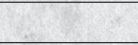 & \\
\hline Gengibre em pó & & 80 & 15 & \\
\hline Goma amoníaca & & 120 & 20 & \\
\hline Goma arábia & & 80 & 15 & \\
\hline Goma em pó & & 120 & 20 & \\
\hline \multicolumn{5}{|l|}{ Goma gálbano, ver Gálbano } \\
\hline \multicolumn{5}{|l|}{ Goma laca, ver Laca } \\
\hline \multicolumn{5}{|l|}{ Goma rom., ver Rom. } \\
\hline \multicolumn{5}{|l|}{ Goma tragacanto, ver Alcatira } \\
\hline Grama & 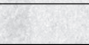 & 10 & & \\
\hline Guaiaco (casca) & 8 & 40 & & \\
\hline Guaiaco (lenho em raspa) & & 20 & & \\
\hline \multicolumn{5}{|l|}{ Guaiaco (goma, ver Extrato) } \\
\hline Guta gamba, ver Rom. & & 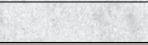 & & + \\
\hline \multicolumn{5}{|c|}{ H } \\
\hline Nome do medicamento & Libra & Onça & Oitava & Grão \\
\hline Heléboro negro (raiz) & 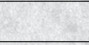 & 50 & & +8 \\
\hline Heléboro negro em pó & 8 & 80 & 30 & + \\
\hline (H)erva terrestre & & 40 & & 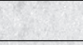 \\
\hline (H)erva-cidreira & & 40 & & \\
\hline (H)erva-doce & & 40 & & 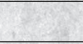 \\
\hline \multicolumn{5}{|c|}{ (H)erva-doce estrelada, ver Anis estrelado } \\
\hline \multicolumn{5}{|l|}{ (H)erva-mularinha, ver Fumária } \\
\hline (H)erva santa (folhas) & 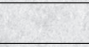 & 10 & & \\
\hline Hortelã apimentada (folhas) & & 100 & & 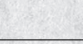 \\
\hline Hortelã vulgar (folhas) & & 20 & + & + \\
\hline Hissopo (folhas e sumidades) & & 60 & & 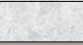 \\
\hline \multicolumn{5}{|c|}{ I } \\
\hline Nome do medicamento & Libra & Onça & Oitava & Grão \\
\hline Incenso (em grão) & & 40 & & \\
\hline Incenso em pó & $x$ & se & 20 & \\
\hline
\end{tabular}


TAXA DOS MEDICAMENTOS SÍMPLICES

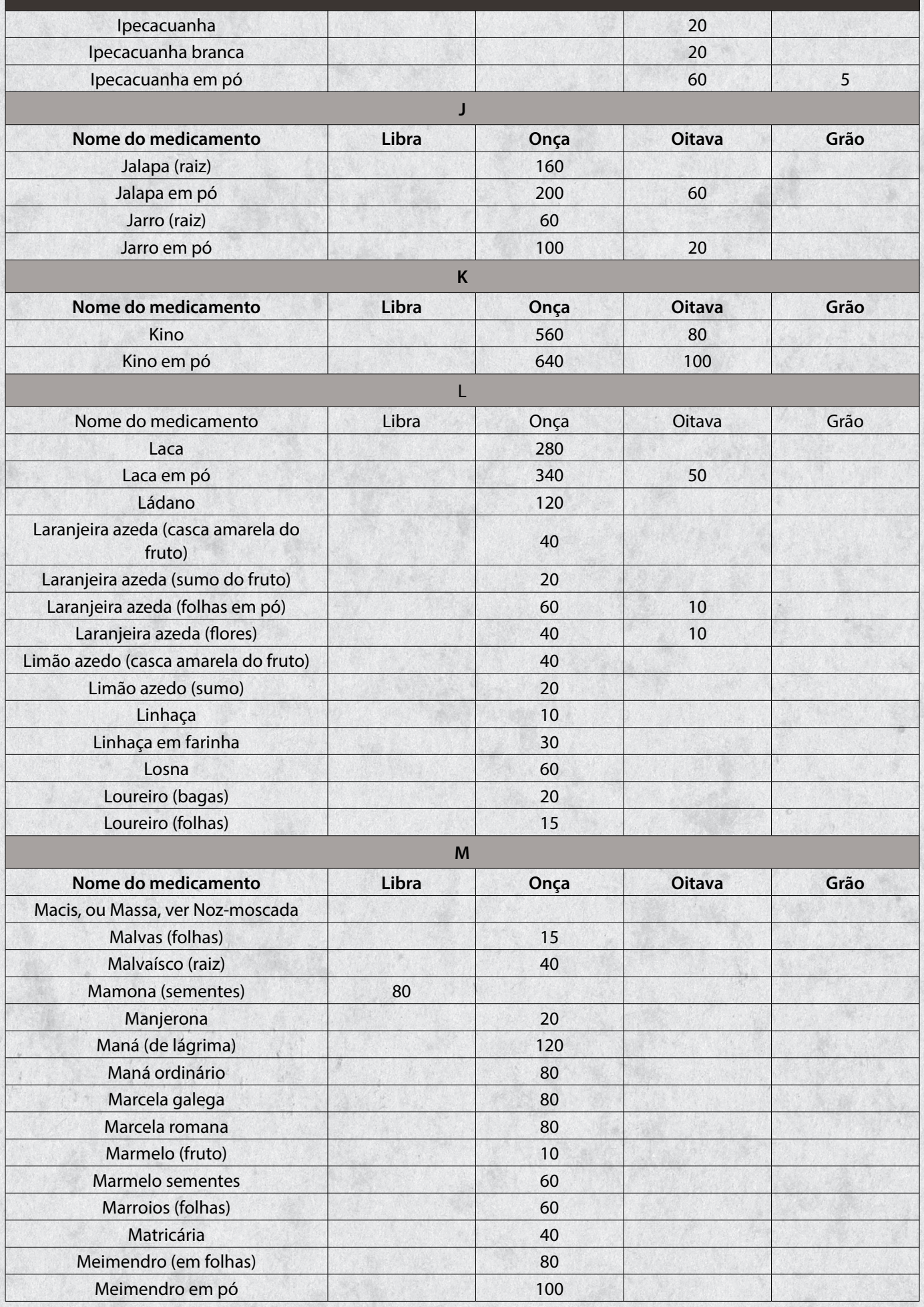




\begin{tabular}{|c|c|c|c|c|}
\hline \multicolumn{5}{|c|}{ TAXA DOS MEDICAMENTOS SÍMPLICES } \\
\hline Mel & 360 & 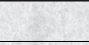 & & \\
\hline Meliloto & & 60 & & \\
\hline Mercúrio, ver Azougue & & +2 & +4 & \\
\hline Mezereão (casca) & & 80 & & \\
\hline Milefólio & & 80 & 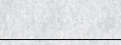 & \\
\hline Mularinha, ver Fumária & + & & 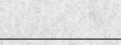 & 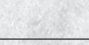 \\
\hline Mostarda (semente) & 240 & & 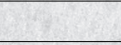 & \\
\hline Mostarda (em pó) & 300 & 40 & +1 & \\
\hline Murta (folhas) & & 40 & & \\
\hline Murta em pó & & 60 & & \\
\hline Murta (bagas) & & 60 & +2 & \\
\hline Musgo islândico & & 320 & 50 & \\
\hline Mirra em (sorte) & 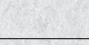 & 100 & 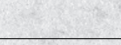 & 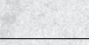 \\
\hline Mirra em pó & & 160 & & \\
\hline \multicolumn{5}{|c|}{$\mathbf{N}$} \\
\hline Nome do medicamento & Libra & Onça & Oitava & Grão \\
\hline Nitro & & 40 & & \\
\hline Nitro em pó & & 60 & 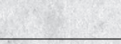 & \\
\hline Noz-moscada (fruto ralado) & & 640 & & \\
\hline Noz-moscada (flor ou macis) & & 720 & & \\
\hline \multicolumn{5}{|c|}{0} \\
\hline Nome do medicamento & Libra & Onça & Oitava & Grão \\
\hline Óleo comum ou azeite & 240 & & & \\
\hline \multicolumn{5}{|l|}{ Óleo petróleo, ver Petróleo } \\
\hline Óleo de vitríolo ou ácido vitriólico & & 40 & & \\
\hline Ópio & & 1280 & & \\
\hline Ópio em pó & 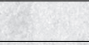 & 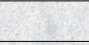 & 200 & 10 \\
\hline Opopânace & 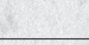 & 320 & & \\
\hline Orégão & & 40 & & \\
\hline Ovo (cada um) & & 20 & +8 & \\
\hline \multicolumn{5}{|c|}{$\mathbf{P}$} \\
\hline Nome do medicamento & Libra & Onça & Oitava & Grão \\
\hline Pau-santo, ver Guaiaco & + & & 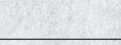 & 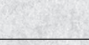 \\
\hline \multicolumn{5}{|l|}{ Papoulas brancas, ver Dormideira } \\
\hline Parreira brava, ver Abutua & 8 & - & & + \\
\hline Pecherim & & 80 & & \\
\hline Pecherim em pó & & 100 & 20 & \\
\hline Pedra calaminar & & 40 & 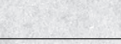 & \\
\hline Pedra-ume, ou ahume & & 20 & 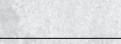 & \\
\hline \multicolumn{5}{|l|}{ Pedra-lipes, ver Vitríolo de cobre } \\
\hline Petróleo & & 80 & & \\
\hline Pês de borgonha & & 140 & & \\
\hline Pimenta-negra em pó & & 80 & & $\underline{2}$ \\
\hline Poejos & & 20 & 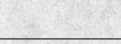 & \\
\hline Píretro (raiz) & & 80 & & \\
\hline Píretro em pó & & 120 & & \\
\hline
\end{tabular}




\section{TAXA DOS MEDICAMENTOS SÍMPLICES}

Q

\begin{tabular}{|c|c|c|c|c|}
\hline Nome do medicamento & Libra & Onça & Oitava & Grão \\
\hline Quássia (lenho) & & 200 & & \\
\hline Quássia raiz & & 100 & & \\
\hline Quássia em pó & & 320 & & \\
\hline Quássia em raspas & 280 & & \\
\hline Quina, ou Casca peruviana & 320 & 40 & \\
\hline Quina-vermelha & 320 & 40 & \\
\hline Quina em pó amarela & 400 & 60 & \\
\hline Quina-vermelha & 400 & 60 & \\
\hline Quina-da-terra & 100 & & \\
\hline Quina em pó & & 160 & 20 & \\
\hline
\end{tabular}

R

\begin{tabular}{|c|c|c|c|c|}
\hline Nome do medicamento & Libra & Onça & Oitava & Grão \\
\hline Rabão rústico (raiz rec.) & & 20 & & 2 \\
\hline Resina amarela & 240 & 20 & & \\
\hline \multicolumn{5}{|l|}{ Rabarbo, ver Ruibarbo } \\
\hline Rom. & & 240 & 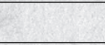 & \\
\hline Rom. em pó & & 280 & & \\
\hline Romeira (casca de fruto) & & 20 & & \\
\hline Romeira flores, ou balaústias & 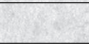 & 80 & & \\
\hline Rosas pálidas & 200 & & & \\
\hline Rosas vermelhas & 360 & & & \\
\hline Rosas em pó & 480 & 80 & 15 & \\
\hline Ruiva (raiz) & & 60 & & \\
\hline Ruiva em pó & & 80 & & \\
\hline Ruibarbo (raiz) & & 360 & 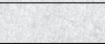 & \\
\hline Ruibarbo em pó & & 440 & 60 & \\
\hline \multicolumn{5}{|c|}{$\mathrm{s}$} \\
\hline Nome do medicamento & Libra & Onça & Oitava & Grão \\
\hline Sabina (folhas) & & 40 & & \\
\hline Sabina em pó & & 60 & + & 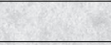 \\
\hline \multicolumn{5}{|l|}{ Saboeira, ver Saponária } \\
\hline Sabugueiro (bagas) & & 60 & & \\
\hline Sabugueiro flores & 4 & 60 & & \\
\hline Sagapeno & & 100 & & \\
\hline Sago, ou Sego & & 80 & & 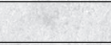 \\
\hline Sago em pó & & 100 & & +2 \\
\hline Sal amargo & & + & & 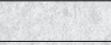 \\
\hline Sal amoníaco (em pó) & & 100 & & \\
\hline Sal catártico amargo & & 25 & 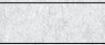 & \\
\hline \multicolumn{5}{|l|}{ Sal d'epson (ver o antecedente) } \\
\hline \multicolumn{5}{|l|}{ Sal de seditz (ver o antecedente) } \\
\hline Sal comum & & 20 & & \\
\hline Sal decrepitado & & 30 & 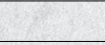 & \\
\hline Salepo (raiz) & & 240 & & \\
\hline Salepo em pó & & 300 & 50 & \\
\hline Salitre, ver Nitro & & & 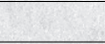 & \\
\hline
\end{tabular}




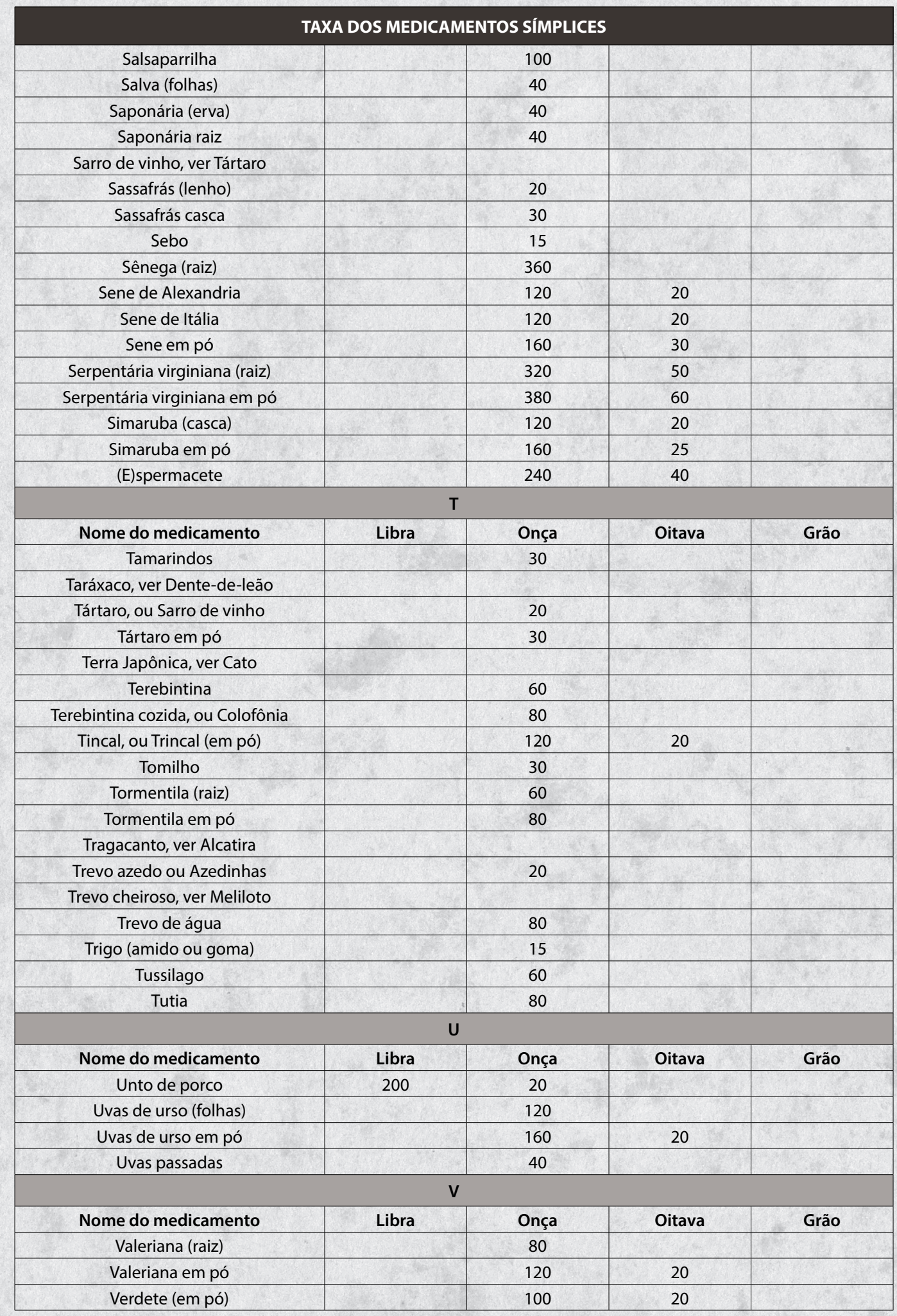




\section{TAXA DOS MEDICAMENTOS SÍMPLICES}

\begin{tabular}{|c|c|c|c|c|}
\hline Verônica (erva) & & 80 & \\
\hline Vinagre & & 80 & & \\
\hline Vinho branco & 160 & & \\
\hline Vinho tinto & 160 & & & \\
\hline Vitríolo branco & & 40 & & \\
\hline Vitríolo de cobre & & & & \\
\hline Vitríolo de Chipre, ver o antecedente & & 20 & & \\
\hline Vitríolo de ferro & & & & \\
\hline Vitríolo verde, ver o antecedente & & & & \\
\hline Vitríolo de zinco, ver Vitríolo branco & & & \\
\hline & Z & & \\
\hline Nome do medicamento & Libra & Onça & Oitava & \\
\hline Zimbro (bagas) & & 80 & & \\
\hline Zinco & & & \\
\hline
\end{tabular}

\section{TAXA DOS MEDICAMENTOS PREPARADOS E COMPOSTOS}

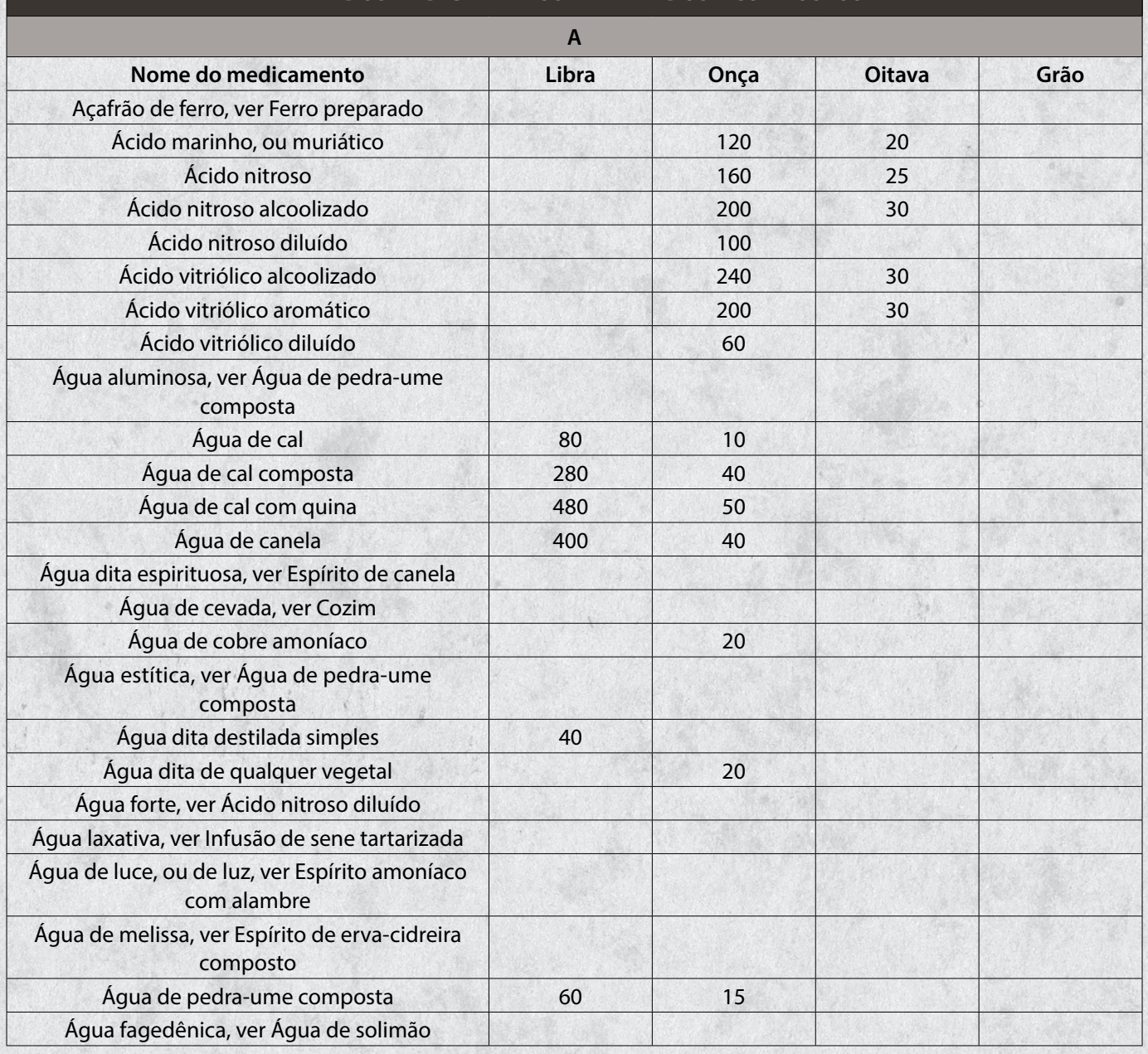




\section{TAXA DOS MEDICAMENTOS PREPARADOS E COMPOSTOS}

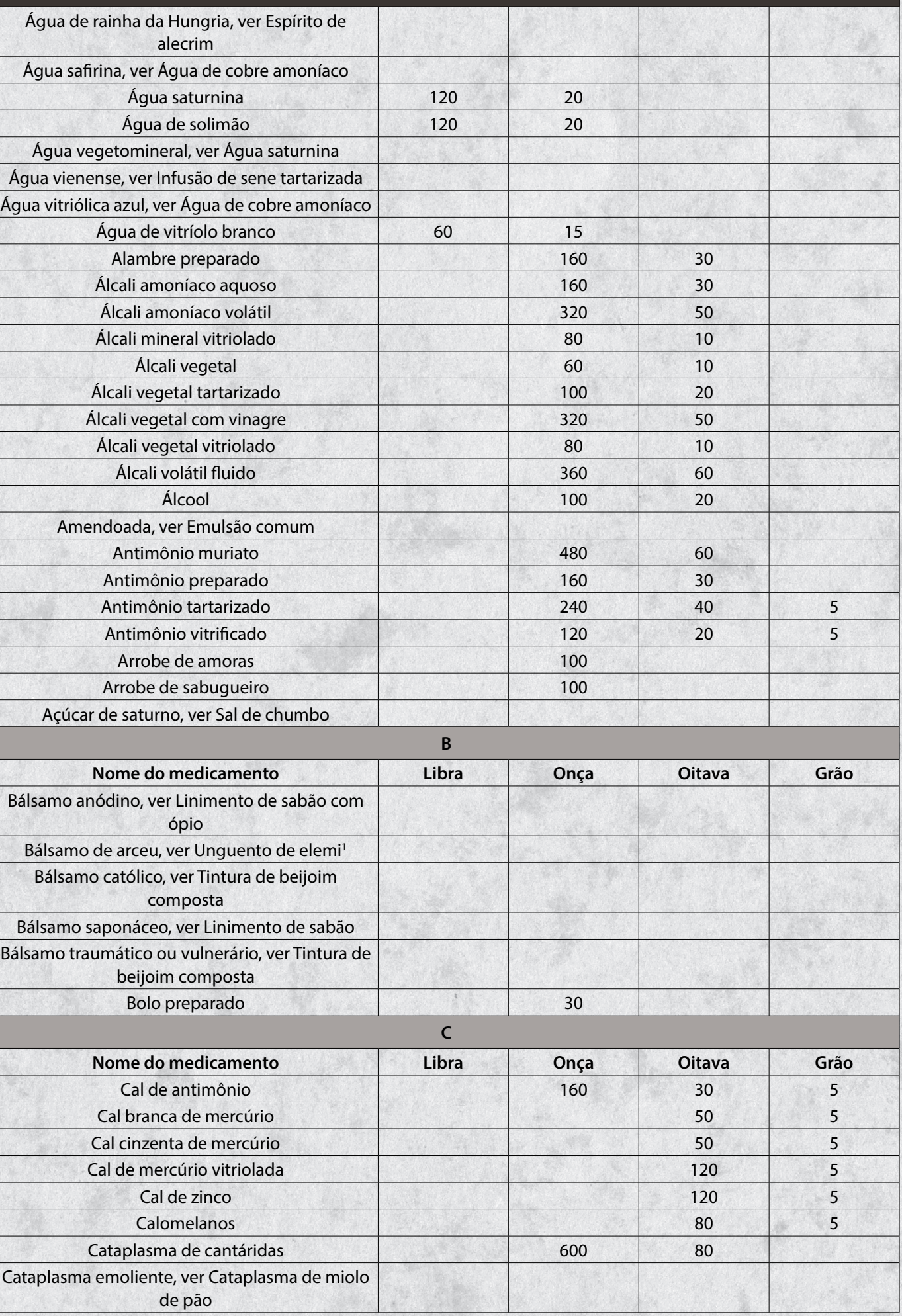




\section{TAXA DOS MEDICAMENTOS PREPARADOS E COMPOSTOS}






\section{TAXA DOS MEDICAMENTOS PREPARADOS E COMPOSTOS}

\begin{tabular}{|c|c|c|c|c|}
\hline Çumo [sumo] de fumária espesso & & & 60 & \\
\hline Çumo [sumo] de meimendro espesso & tenta & 120 & 20 & \\
\hline Çumo [sumo] de taráxaco espesso & & 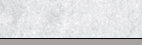 & 40 & \\
\hline \multicolumn{5}{|c|}{$\mathbf{E}$} \\
\hline Nome do medicamento & Libra & Onça & Oitava & Grão \\
\hline Eletuário aromático & & 240 & 40 & \\
\hline Eletuário de canafístula & & 80 & 15 & \\
\hline Eletuário de cato & 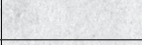 & 300 & 60 & \\
\hline \multicolumn{5}{|l|}{ Eletuário lenitivo, ver Eletuário de sene } \\
\hline Eletuário opiado & & 360 & 60 & \\
\hline Eletuário de sene & & 160 & 30 & \\
\hline \multicolumn{5}{|l|}{$\begin{array}{c}\text { Elixir ácido de vitríolo, ver Ácido vitriólico } \\
\text { aromático }\end{array}$} \\
\hline \multicolumn{5}{|l|}{ Elixir guaiacino, ver Tintura de guaiaco } \\
\hline \multicolumn{5}{|l|}{$\begin{array}{l}\text { Eletuário dito volátil, ver Tintura de guaiaco } \\
\text { amoniacal }\end{array}$} \\
\hline \multicolumn{5}{|l|}{$\begin{array}{l}\text { Eletuário paregórico, ver Tintura de ópio } \\
\text { alcanforada }\end{array}$} \\
\hline \multicolumn{5}{|l|}{$\begin{array}{l}\text { Eletuário proprietatis, ver Tintura de azebre } \\
\text { composta }\end{array}$} \\
\hline \multicolumn{5}{|l|}{$\begin{array}{l}\text { Eletuário de saúde, ver Tintura de sene } \\
\text { composta }\end{array}$} \\
\hline \multicolumn{5}{|l|}{$\begin{array}{l}\text { Eletuário estomacal, ver Tintura de genciana } \\
\text { composta }\end{array}$} \\
\hline \multicolumn{5}{|l|}{$\begin{array}{l}\text { Emplastro adesivo, ver Emplastro comum com } \\
\text { resina }\end{array}$} \\
\hline Emplastro de cantáridas & 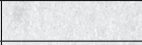 & 600 & 100 & \\
\hline Emplastro de cicuta & & 170 & 30 & \\
\hline Emplastro comum & 240 & 30 & & \\
\hline Emplastro dito gomado & 720 & 80 & & \\
\hline Emplastro dito resina & 360 & 60 & & \\
\hline \multicolumn{5}{|l|}{$\begin{array}{l}\text { Emplastro de aquilão menor, ver Emplastro } \\
\text { comum }\end{array}$} \\
\hline \multicolumn{5}{|l|}{$\begin{array}{l}\text { Emplastro de aquilão gomado, ver Emplastro } \\
\text { comum gomado }\end{array}$} \\
\hline Emplastro de ládano & & 240 & & \\
\hline Emplastro de meimendro & 1200 & 120 & & \\
\hline Emplastro de mercurial & & 200 & & \\
\hline Emplastro de sabão & & 80 & & \\
\hline \multicolumn{5}{|l|}{ Emplastro estomacal, ver Emplastro de ládano } \\
\hline \multicolumn{5}{|l|}{$\begin{array}{l}\text { Emplastro vesicatório, ver Emplastro de } \\
\text { cantáridas }\end{array}$} \\
\hline Emulsão alcanforada & 240 & 30 & & \\
\hline Emulsão almiscarada & & 160 & & \\
\hline Emulsão arábica & 160 & 20 & & \\
\hline Emulsão comum & 120 & 20 & 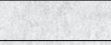 & \\
\hline Enxofre de antimônio precipitado & & & 160 & \\
\hline \multicolumn{5}{|l|}{ Enxofre dourado d'antimônio, ver antecedente } \\
\hline Espírito de alecrim & & 80 & & \\
\hline Espírito de alfazema & $x$ & 80 & & \\
\hline
\end{tabular}




\section{TAXA DOS MEDICAMENTOS PREPARADOS E COMPOSTOS}

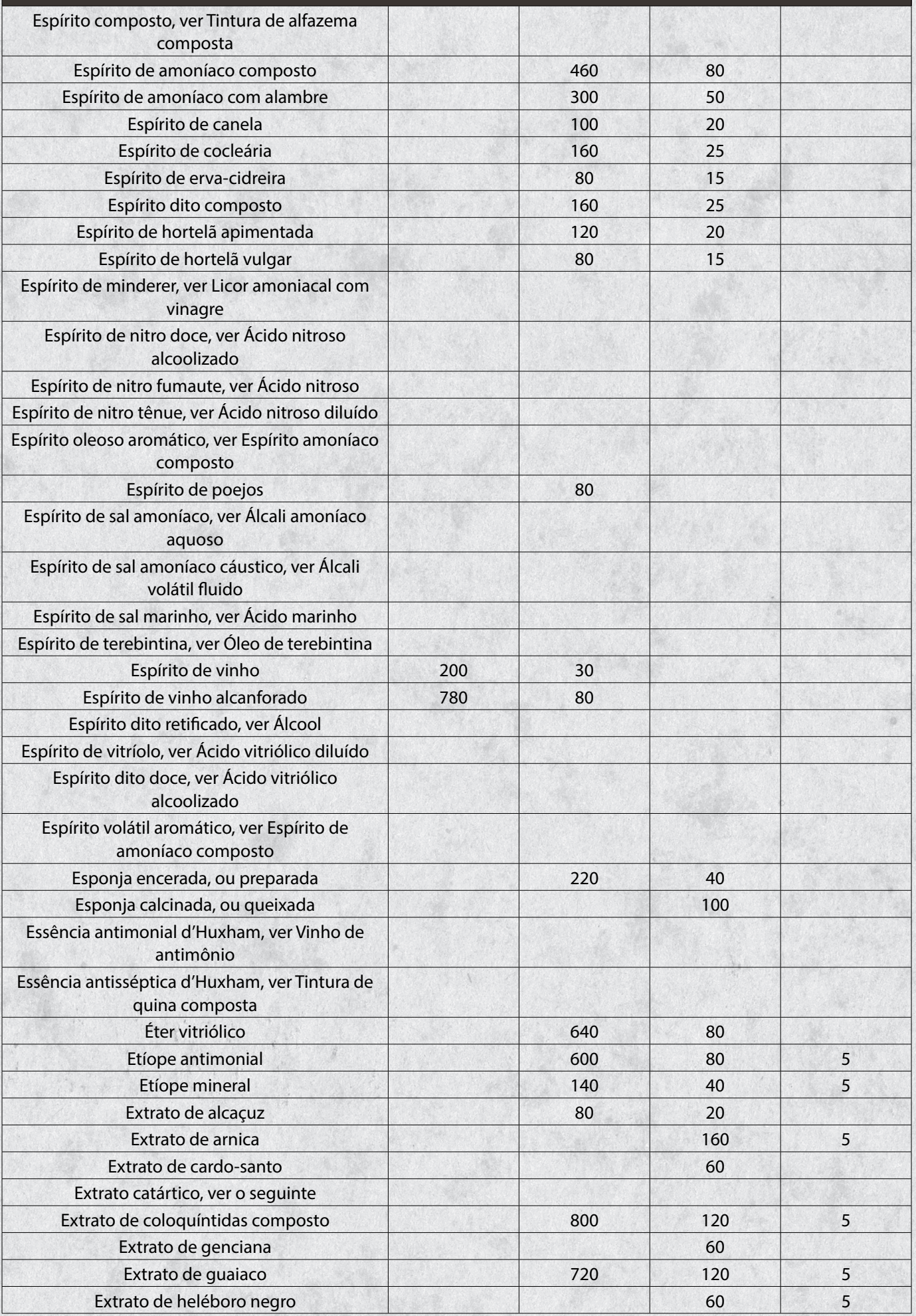




\section{TAXA DOS MEDICAMENTOS PREPARADOS E COMPOSTOS}

\begin{tabular}{|c|c|c|c|}
\hline Extrato de jalapa & & 120 & 5 \\
\hline Extrato de losna & & 60 & \\
\hline Extrato de marroios & & 60 & 20 \\
\hline Extrato de ópio gomoso & & 960 & 15 \\
\hline Extrato de pão de quássia & & 720 & 5 \\
\hline Extrato de quina peruviana & & 160 & 5 \\
\hline Extrato de ruibarbo & & 240 & \\
\hline Extrato de saturno, ver Vinagre de chumbo & & & \\
\hline Extrato de taráxaco & & & \\
\hline Extrato de tebaico, ver Ópio purificado & & & \\
\hline
\end{tabular}

\begin{tabular}{|c|c|c|c|c|}
\hline Nome do medicamento & Libra & Onça & Oitava & Grão \\
\hline Ferro amoniacal & & & 120 & 5 \\
\hline Ferro preparado & & 100 & 20 & \\
\hline Ferro tartarizado & & 120 & 20 & \\
\hline Ferro vitriolado & & 120 & 20 & \\
\hline Ferrugem de ferro, ver Ferro preparado & & & & \\
\hline $\begin{array}{c}\text { Flores de sal amoníaco marciais, ver Ferro } \\
\text { amoniacal }\end{array}$ & & & & \\
\hline Flores de zinco, ver Cal de zinco & & & & \\
\hline
\end{tabular}

\begin{tabular}{|c|c|c|c|c|}
\hline \multicolumn{5}{|c|}{ G } \\
\hline Nome do medicamento & Libra & Onça & Oitava & Grão \\
\hline Geleia de musgo islândico & 1400 & 150 & & \\
\hline Geleia de ponta de veado & 600 & 80 & & \\
\hline Geleia de sagu & 480 & 50 & & \\
\hline Geleia de salepo & 600 & 80 & & \\
\hline Goma amoníaca depurada & & 180 & 30 & \\
\hline \multicolumn{5}{|c|}{ I } \\
\hline Nome do medicamento & Libra & Onça & Oitava & Grão \\
\hline \multicolumn{5}{|l|}{$\begin{array}{l}\text { Infusão amarga, ver Infusão de genciana } \\
\text { composta }\end{array}$} \\
\hline Infusão fria de quina & 400 & 50 & & \\
\hline Infusão fria de quássia & 160 & 20 & & \\
\hline Infusão de genciana composta & 100 & 20 & & \\
\hline Infusão de ruibarbo & 600 & 60 & & \\
\hline Infusão de sene simples & 240 & 30 & & \\
\hline Infusão de sene tartarizada & 650 & 60 & & \\
\hline Infusão de tamarindos composta & 460 & 50 & & \\
\hline \multicolumn{5}{|c|}{ K } \\
\hline Nome do medicamento & Libra & Onça & Oitava & Grão \\
\hline \multicolumn{5}{|l|}{$\begin{array}{l}\text { Kermes mineral, ver Enxofre de antimônio } \\
\text { precipitado }\end{array}$} \\
\hline \multicolumn{5}{|c|}{$\mathbf{L}$} \\
\hline Nome do medicamento & Libra & Onça & Oitava & Grão \\
\hline Láudano líquido, ver Tintura de ópio & & & & +2 \\
\hline Láudano opiado, ver Ópio purificado & 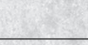 & & & \\
\hline \multicolumn{5}{|l|}{ Leite de amêndoas, ver Emulsão comum } \\
\hline Leite de amoníaco & 120 & 15 & & \\
\hline
\end{tabular}




\section{TAXA DOS MEDICAMENTOS PREPARADOS E COMPOSTOS}

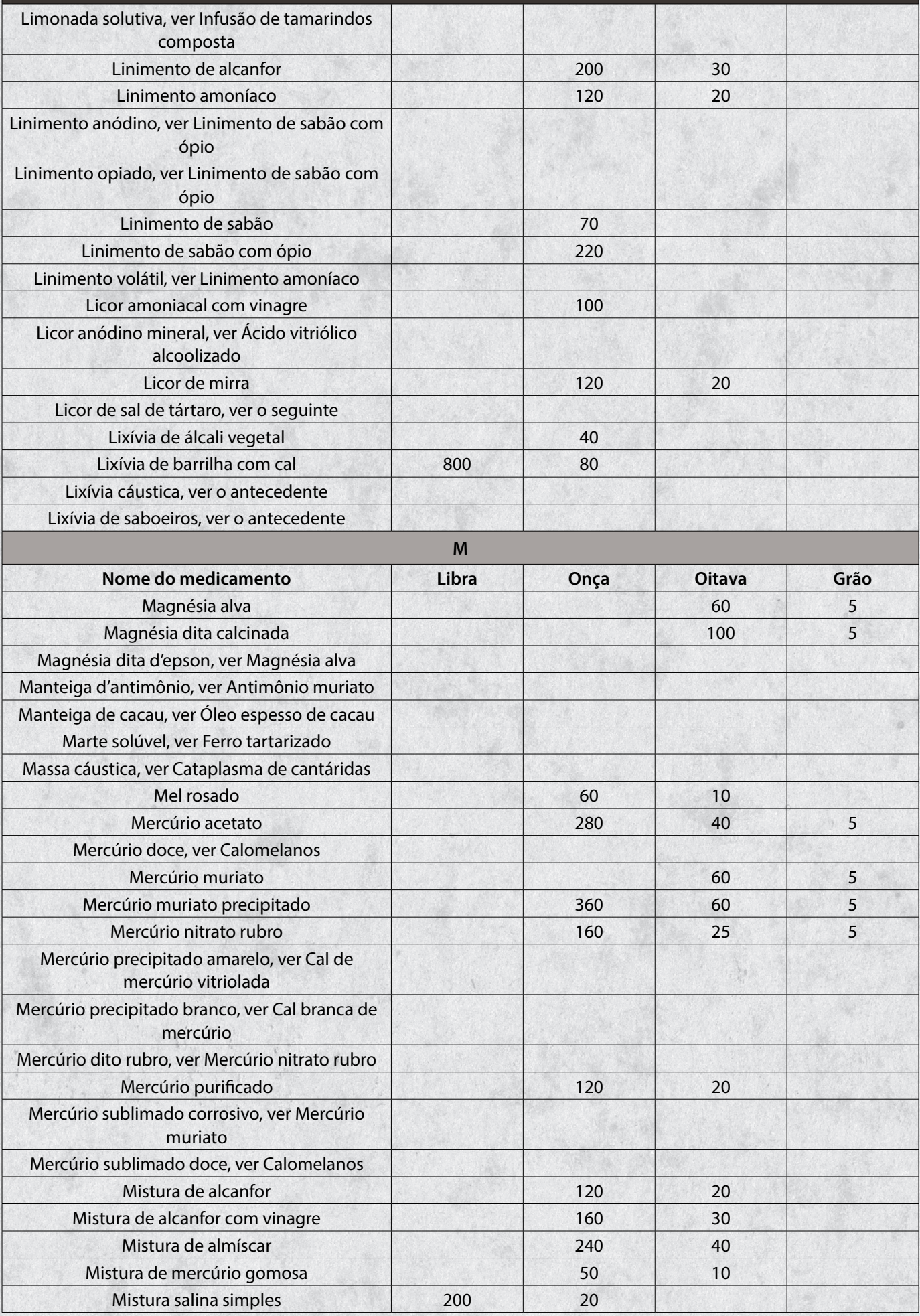




\section{TAXA DOS MEDICAMENTOS PREPARADOS E COMPOSTOS}

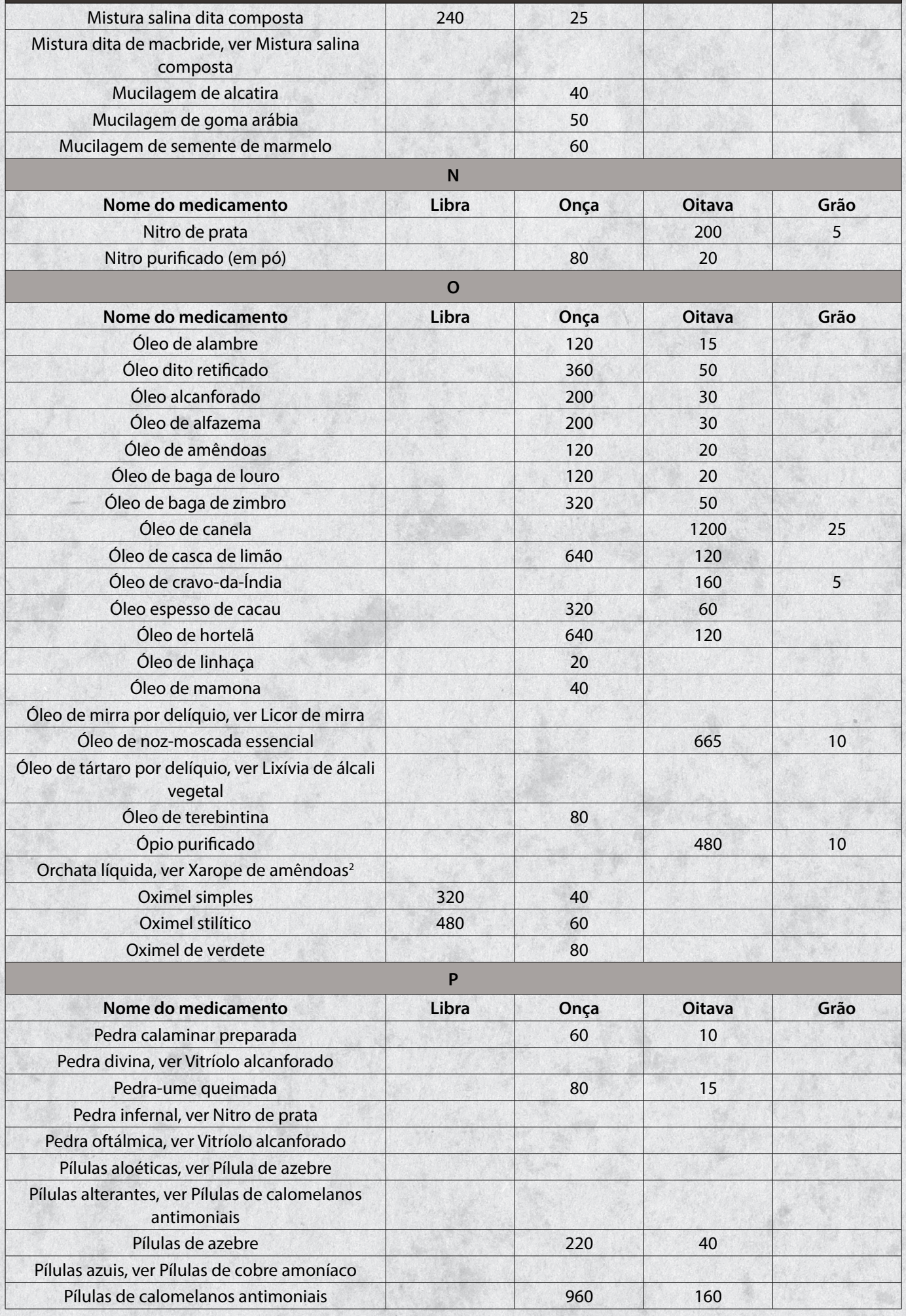




\section{TAXA DOS MEDICAMENTOS PREPARADOS E COMPOSTOS}

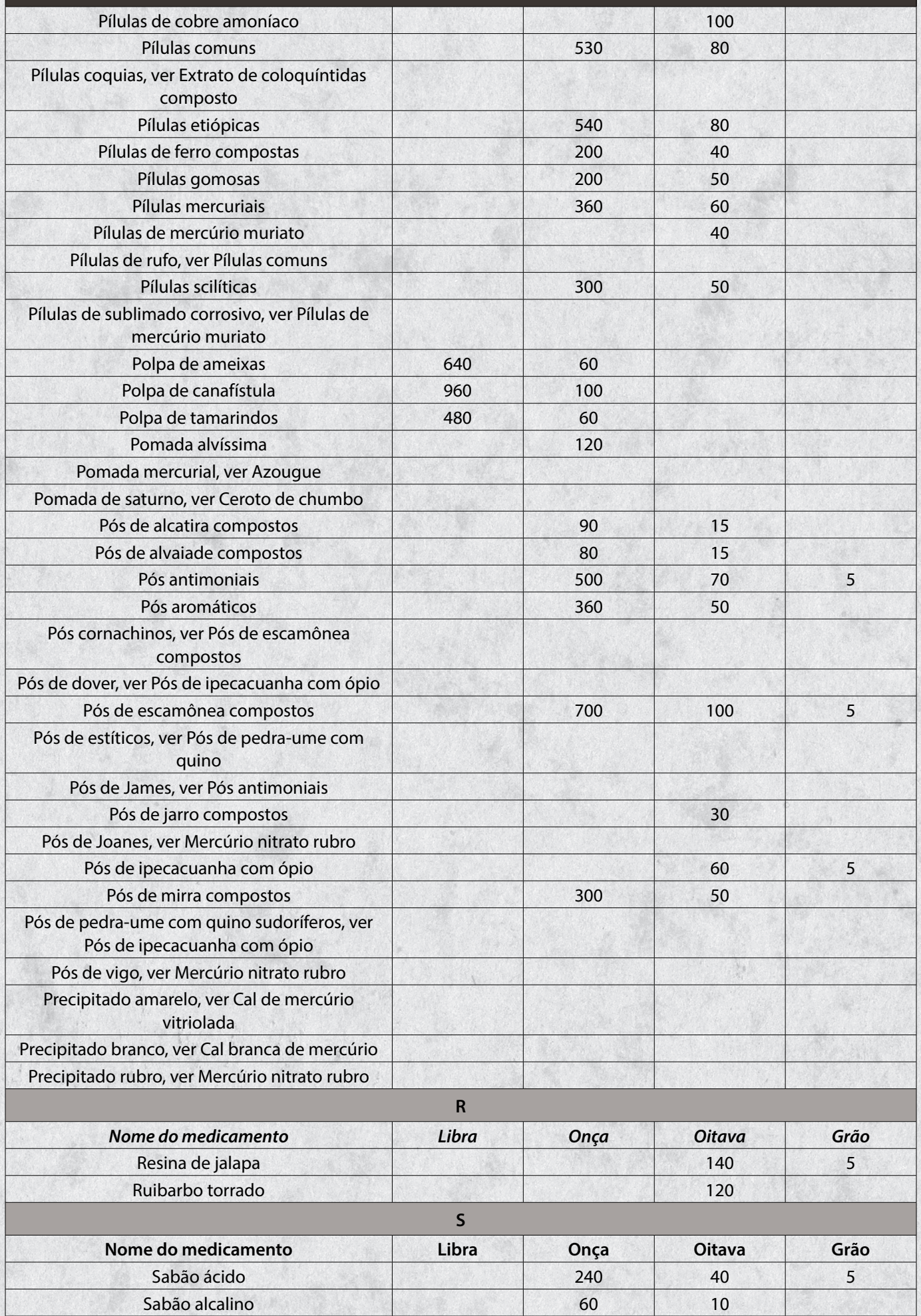




\section{TAXA DOS MEDICAMENTOS PREPARADOS E COMPOSTOS}

\begin{tabular}{|c|c|c|c|c|}
\hline Sal de alambre & & & 240 & 5 \\
\hline Sal amoníaco purificado & & & 20 & 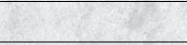 \\
\hline Sal catártico, ver Álcali mineral vitriolado & & & 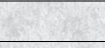 & 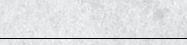 \\
\hline Sal de chumbo & & 80 & 20 & \\
\hline \multicolumn{5}{|l|}{ Sal diurético, ver Álcali vegetal com vinagre } \\
\hline \multicolumn{5}{|l|}{ Sal de ferro, ver Ferro vitriolado } \\
\hline \multicolumn{5}{|l|}{ Sal tartarizado, ver Ferro tartarizado } \\
\hline \multicolumn{5}{|l|}{ Sal de Glauber, ver Álcali mineral vitriolado } \\
\hline \multicolumn{5}{|l|}{ Sal de marte, ver Ferro vitriolado } \\
\hline \multicolumn{5}{|l|}{ Sal de mercúrio acetoso, ver Mercúrio acetato } \\
\hline \multicolumn{5}{|l|}{ Sal policresto, ver Álcali mineral vitriolado } \\
\hline \multicolumn{5}{|l|}{ Sal de Saturno, ver Sal de chumbo } \\
\hline Sal de tártaro, ver Álcali vegetal & & & 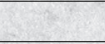 & \\
\hline \multicolumn{5}{|l|}{$\begin{array}{c}\text { Sal volátil de sal amoníaco, ver Álcali amoníaco } \\
\text { volátil }\end{array}$} \\
\hline Sebo preparado & & 20 & & \\
\hline \multicolumn{5}{|l|}{ Solimão, ver Mercúrio muriato } \\
\hline \multicolumn{5}{|l|}{ Solução de mercúrio gomosa, ver Mistura etc. } \\
\hline \multicolumn{5}{|l|}{$\begin{array}{l}\text { Soro de leite aluminoso, ver Soro de leite com } \\
\text { pedra-ume }\end{array}$} \\
\hline Soro de leite clarificado & 120 & 15 & & \\
\hline Soro de leite com mostarda & 120 & 15 & & \\
\hline Soro de leite com pedra-ume & 120 & 15 & 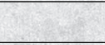 & \\
\hline Soro vinhoso & 140 & 20 & & \\
\hline \multicolumn{5}{|c|}{$T$} \\
\hline Nome do medicamento & Libra & Onça & Oitava & Grão \\
\hline \multicolumn{5}{|l|}{ Tártaro antimonial, ver Antimônio tartarizado } \\
\hline \multicolumn{5}{|l|}{ Tártaro emético, ver Antimônio tartarizado } \\
\hline \multicolumn{5}{|l|}{ Tártaro marcial solúvel, ver Ferro tartarizado } \\
\hline \multicolumn{5}{|l|}{$\begin{array}{c}\text { Tártaro regenerado, ver Álcali vegetal com } \\
\text { vinagre }\end{array}$} \\
\hline \multicolumn{5}{|l|}{ Tártaro solúvel, ver Álcali vegetal tartarizado } \\
\hline \multicolumn{5}{|l|}{ Tártaro estibiado, ver Antimônio tartarizado } \\
\hline \multicolumn{5}{|l|}{ Tártaro vitriolado, ver Álcali vegetal vitriolado } \\
\hline \multicolumn{5}{|l|}{$\begin{array}{c}\text { Terra foliada de tártaro, ver Álcali vegetal com } \\
\text { vinagre }\end{array}$} \\
\hline \multicolumn{5}{|l|}{ Teriaga, ver Eletuário opiado } \\
\hline Tintura de alfazema composta & 4 & 120 & 20 & \\
\hline \multicolumn{5}{|l|}{$\begin{array}{c}\text { Tintura amarga, ver Tintura de genciana } \\
\text { composta }\end{array}$} \\
\hline Tintura aromática & & 80 & 20 & \\
\hline Tintura de azebre composta & & 360 & 60 & \\
\hline Tintura de bálsamo peruviano & & 160 & 30 & +2 \\
\hline Tintura de beijoim composta & & 120 & 20 & \\
\hline Tintura de calumba & & 50 & 10 & \\
\hline \multicolumn{5}{|l|}{$\begin{array}{c}\text { Tintura de canela composta, ver Tintura } \\
\text { aromática }\end{array}$} \\
\hline Tintura de cantáridas & 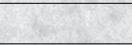 & 80 & 20 & \\
\hline Tintura de castóreo & s. & 100 & 20 & \\
\hline
\end{tabular}




\section{TAXA DOS MEDICAMENTOS PREPARADOS E COMPOSTOS}

\begin{tabular}{|c|c|c|c|c|}
\hline Tintura dita composta & & 300 & 50 & \\
\hline \multicolumn{5}{|l|}{ Tintura fétida, ver a antecedente } \\
\hline Tintura de genciana composta & & 50 & & \\
\hline \multicolumn{5}{|l|}{$\begin{array}{l}\text { Tintura gengival balsâmica, ver Tintura de mirra } \\
\text { composta }\end{array}$} \\
\hline Tintura de guaiaco & & 400 & 60 & \\
\hline Tintura dita amoniacal & & 580 & 80 & \\
\hline Tintura de heléboro negro & & 40 & 10 & \\
\hline Tintura de jalapa & & 150 & 30 & \\
\hline Tintura de quino & & 140 & 20 & \\
\hline Tintura de laca composta & & 220 & 30 & \\
\hline Tintura de mirra & & 100 & 20 & \\
\hline Tintura de mirra dita composta & & 200 & 30 & \\
\hline Tintura de ópio & & 60 & 10 & 5 \\
\hline Tintura dita alcanforada & & 300 & 50 & \\
\hline Tintura de quina composta & & 120 & 20 & \\
\hline Tintura de ruibarbo & & 100 & 20 & \\
\hline Tintura dita composta & & 160 & 30 & \\
\hline \multicolumn{5}{|l|}{ Tintura sacra, ver Vinho de azebre } \\
\hline Tintura de sene composta & & 60 & 20 & \\
\hline \multicolumn{5}{|l|}{ Tebaica, ver Tintura de ópio } \\
\hline Tebaica de valeriana volátil & & 500 & 80 & 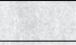 \\
\hline Trociscos de alcaçuz & & 120 & 20 & a \\
\hline Trociscos ditos com ópio & & 160 & 30 & \\
\hline \multicolumn{5}{|l|}{$\begin{array}{l}\text { Trociscos béquicos brancos, ver Pós de alcatira } \\
\text { compostos }\end{array}$} \\
\hline \multicolumn{5}{|l|}{ Trociscos ditos negros, ver Trociscos de alcaçuz } \\
\hline \multicolumn{5}{|l|}{$\begin{array}{c}\text { Trociscos brancos de rases, ver Pós de alvaiade } \\
\text { compostos }\end{array}$} \\
\hline Trociscos de magnésia & & 300 & 60 & \\
\hline \multicolumn{5}{|l|}{ Trociscos de mirra, ver Pós de mirra compostos } \\
\hline \multicolumn{5}{|l|}{ Turbith-mineral, ver Cal de mercúrio vitriolada } \\
\hline Tutia preparada & & 100 & 20 & \\
\hline \multicolumn{5}{|c|}{ V } \\
\hline Nome do medicamento & Libra & Onça & Oitava & Grão \\
\hline \multicolumn{5}{|l|}{ Vidro de antimônio, ver Antimônio vitrificado } \\
\hline Vinagre de alfazema & 180 & 20 & & \\
\hline \multicolumn{5}{|l|}{ Vinagre antisséptico, ver o seguinte } \\
\hline Vinagre aromático & 190 & 20 & & \\
\hline Vinagre de arruda & 190 & 20 & & \\
\hline Vinagre de chumbo & 200 & 30 & & \\
\hline Vinagre de cólquico & 200 & 30 & & \\
\hline \multicolumn{5}{|l|}{$\begin{array}{l}\text { Vinagre dos quatro ladrões, ver Vinagre } \\
\text { aromático }\end{array}$} \\
\hline Vinagre de rosas & 220 & 30 & & \\
\hline Vinagre de sabugueiro & 220 & 30 & & \\
\hline \multicolumn{5}{|l|}{ Vinagre de Saturno, ver Vinagre de chumbo } \\
\hline Vinagre squilítico & 340 & 40 & & \\
\hline Vinho amargo, ver Vinho de quina composto 3 & & & & \\
\hline
\end{tabular}




\section{TAXA DOS MEDICAMENTOS PREPARADOS E COMPOSTOS}

\begin{tabular}{|c|c|c|c|c|}
\hline Vinho de antimônio & & 40 & 10 & 5 \\
\hline Vinho dito tartarizado & 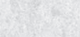 & 40 & 10 & 5 \\
\hline Vinho de azebre & & 60 & 10 & \\
\hline \multicolumn{5}{|c|}{ Vinho chalibiado, ver Vinho de ferro ${ }^{4}$} \\
\hline Vinho de dedaleira & & 40 & & \\
\hline \multicolumn{5}{|c|}{ Vinho emético, ver Vinho de antimônio } \\
\hline \multicolumn{5}{|c|}{$\mathrm{X}$} \\
\hline Nome do medicamento & Libra & Onça & Oitava & Grão \\
\hline \multicolumn{5}{|c|}{ Xarope de papoilas brancas, ver o mesmo } \\
\hline Xarope de ruibarbo & 480 & 60 & & \\
\hline \multicolumn{5}{|c|}{ Xarope simples, ver Xarope comum } \\
\hline Xarope de vinagre & 250 & 30 & & \\
\hline
\end{tabular}

Notas:

${ }^{1}$ Não há correspondência da taxa deste medicamento no Regimento dos preços dos medicamentos...

${ }^{2}$ Ver taxa para Xarope simples.

${ }^{3}$ Não há correspondência da taxa deste medicamento no Regimento dos preços dos medicamentos...

${ }^{4}$ Não há correspondência da taxa deste medicamento no Regimento dos preços dos medicamentos...

\section{TAXA DAS PREPARAÇŌES E COMPOSIÇÕES DOS MEDICAMENTOS EM SI MESMAS}

\begin{tabular}{|c|c|c|c|c|}
\hline Preparações e composições & Libra & Onça & Oitava & Grão \\
\hline Por fazer a mistura de cada onça de pós compostos & & 20 & & \\
\hline Por cada libra de infusão, tintura, mistura e linimento & 30 & & & \\
\hline Por cada libra de cozimento & 60 & & & \\
\hline Por cada libra de cozimento estratificado & 160 & & & \\
\hline Por cada onça de eletuário, pílulas ou de trociscos & & 40 & & \\
\hline Por dourar cada onça de pílulas & & 120 & & \\
\hline Por pratear cada onça de pílulas & & 40 & & \\
\hline Por fazer cada libra de polpa & 100 & & & \\
\hline Por fazer cada libra de conserva & 60 & & & \\
\hline Por fazer cada libra de cataplasma cozida & 120 & & & \\
\hline Por fazer cada libra dita crua & 40 & & & \\
\hline Por fazer cada libra de unguento, ceroto ou emplastro & 60 & & & \\
\hline simples & & & \\
\hline Por fazer cada libra de emplastro com extinção de & 240 & & \\
\hline azougue & 240 & & & \\
\hline Por fazer sumo espesso e de geleia & 240 & & & \\
\hline Por fazer cada libra de xarope sem cozimento & 30 & & & \\
\hline Por fazer cada libra de xarope dito cozido & 80 & & & \\
\hline Por fazer cada onça de qualquer sumo espremido de & 40 & & & \\
\hline planta recente & 40 & & & \\
\hline Porificar cada libra de qualquer líquido & 50 & & \\
\hline
\end{tabular}

